\title{
Evaluation of Experimental Parameters in the Accelerated Aging of Closed-Cell Foam Insulation
}

December 2012

Prepared by

Therese Stovall

Michael Vanderlen

Jerald Atchley 


\title{
DOCUMENT AVAILABILITY
}

Reports produced after January 1, 1996, are generally available free via the U.S. Department of Energy (DOE) Information Bridge.

Web site http://www.osti.gov/bridge

Reports produced before January 1, 1996, may be purchased by members of the public from the following source.

\author{
National Technical Information Service \\ 5285 Port Royal Road \\ Springfield, VA 22161 \\ Telephone 703-605-6000 (1-800-553-6847) \\ TDD 703-487-4639 \\ Fax 703-605-6900 \\ E-mail info@ntis.gov \\ Web site http://www.ntis.gov/support/ordernowabout.htm
}

Reports are available to DOE employees, DOE contractors, Energy Technology Data Exchange (ETDE) representatives, and International Nuclear Information System (INIS) representatives from the following source.

Office of Scientific and Technical Information

P.O. Box 62

Oak Ridge, TN 37831

Telephone 865-576-8401

Fax 865-576-5728

E-mail reports@osti.gov

Web site http://www.osti.gov/contact.html

This report was prepared as an account of work sponsored by an agency of the United States Government. Neither the United States Government nor any agency thereof, nor any of their employees, makes any warranty, express or implied, or assumes any legal liability or responsibility for the accuracy, completeness, or usefulness of any information, apparatus, product, or process disclosed, or represents that its use would not infringe privately owned rights. Reference herein to any specific commercial product, process, or service by trade name, trademark, manufacturer, or otherwise, does not necessarily constitute or imply its endorsement, recommendation, or favoring by the United States Government or any agency thereof. The views and opinions of authors expressed herein do not necessarily state or reflect those of the United States Government or any agency thereof. 
Energy and Transportation Science Division

Building Envelope Research

\author{
Therese Stovall \\ Michael Vanderlan \\ Jerald Atchley
}

Date Published: November 2012

\author{
Prepared by \\ OAK RIDGE NATIONAL LABORATORY \\ Oak Ridge, Tennessee 37831-6283 \\ managed by \\ UT-BATTELLE, LLC \\ for the \\ U.S. DEPARTMENT OF ENERGY \\ under contract DE-AC05-00OR22725
}




\section{CONTENTS}

Page

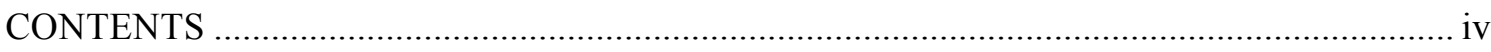

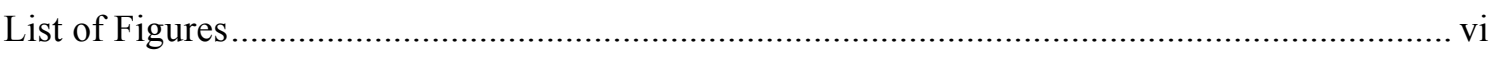

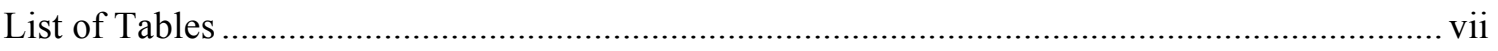

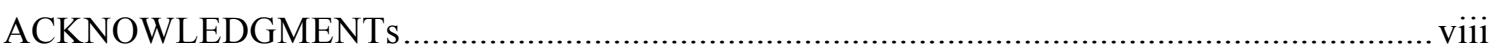

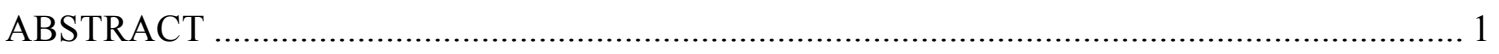

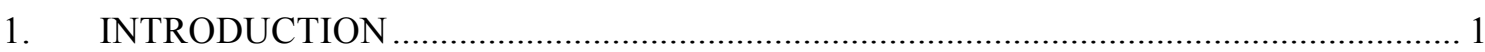

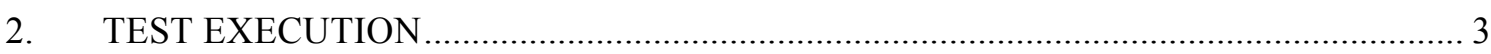

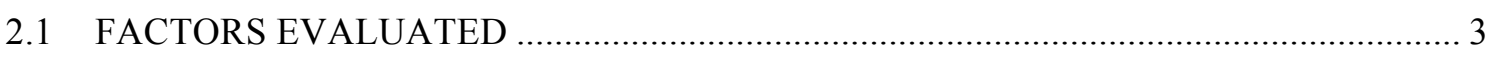

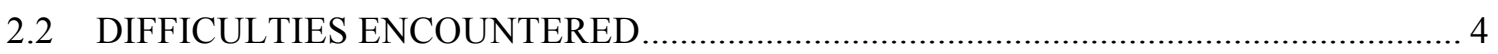

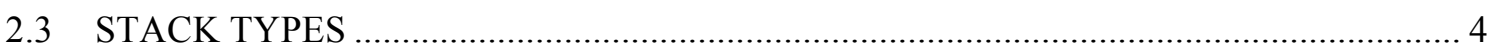

2.4 THERMAL CONDUCTIVITY MEASUREMENTS …................................................. 5

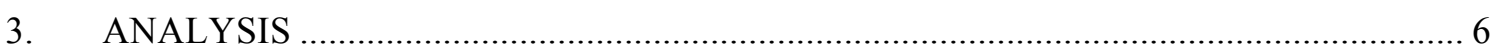

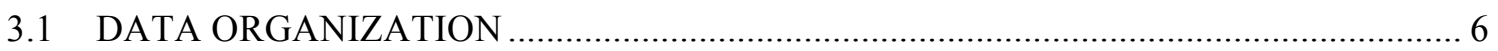

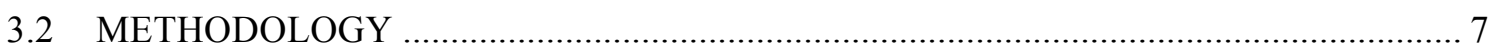

4. PRESCRIPTIVE TEST METHOD RESULTS ............................................................ 8

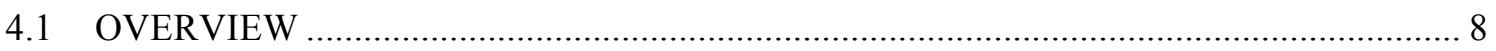

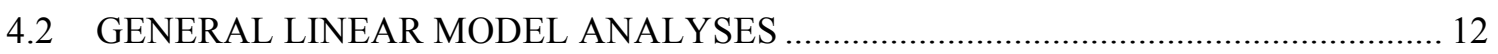

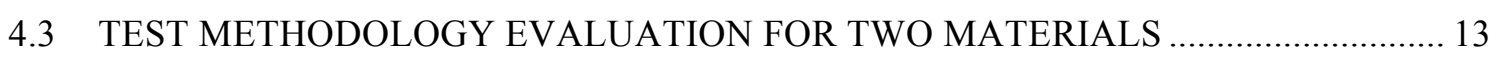

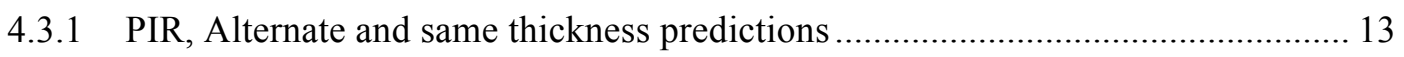

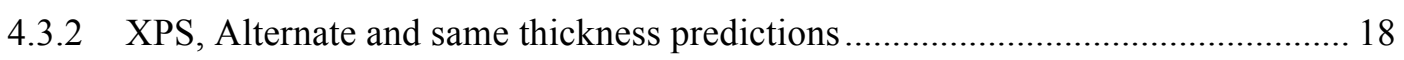

4.3.3 Data distributions for PIR and XPS boardstock for selected test method options. 20

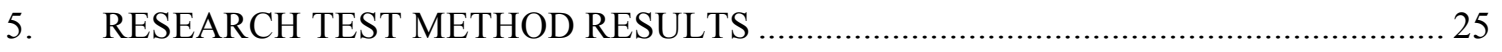

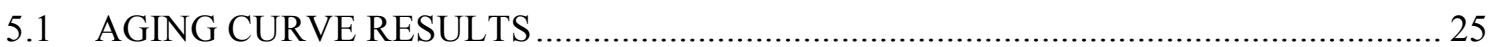

5.2 MAGNITUDE OF ERRORS DUE TO THE DESTRUCTION OF SURFACE LAYER

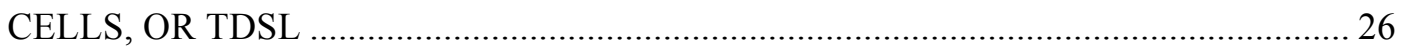

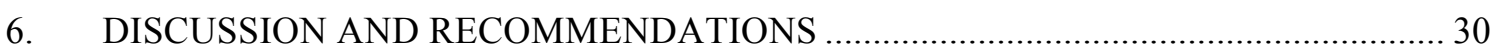

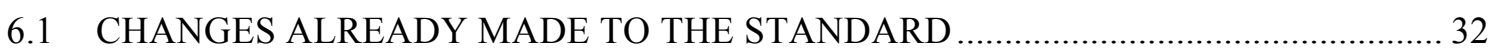

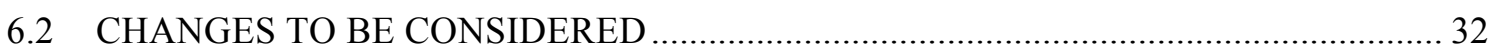

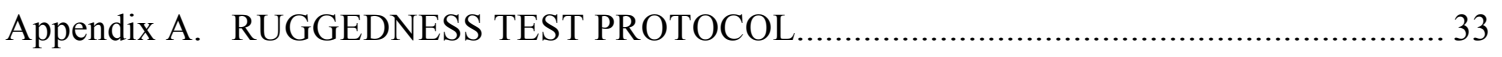

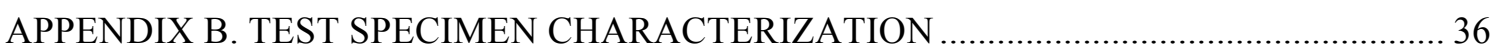

B.1 TEST SPECIMEN PREPARATION [FROM STOVALL AND BOGDAN, 2007] ............ 36

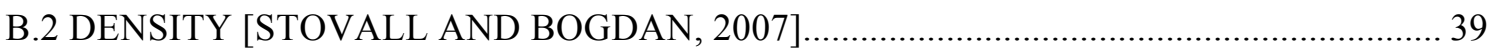


B.3 HOMOGENEITY AND ALTERNATE PRODUCT THICKNESS

B.4 THICKNESS OF THE DESTROYED SURFACE LAYER [STOVALL AND BOGDAN, 2007]

Appendix C. C1303-2007 QUALIFICATION REQUIREMENTS AND PROPOSED MODIFICATIONS TO THOSE REQUIREMENTS . 43

C.1 HOMOGENEITY.

C.2 ALTERNATE PRODUCT THICKNESS QUALIFICATION. 45

References... 


\section{LIST OF FIGURES}

Figure 1 Diagram of stack design, Surface stack (left), Profile Mixed stack (right) ............... 5

Figure 2 Unscreened dataset, range of values for PIR and XPS for alternate thickness comparisons and same thickness comparisons.....

Figure 3 Unscreened dataset, range of values for PIR and XPS for both comparisons (same and alternate thickness) for five stack types.

Figure 4 Unscreened dataset, looking at homogeneity based on aging as defined in the 2010 version of ASTM C1303. Shaded area represents "better" homogeneity.

Figure 5 Dataset confined to mathematical stack only, looking at proposed "simplified" homogeneity measure based on a comparison of core and surface thermal conductivity at 30 days $/ \mathrm{cm}^{2}$....

Figure 6 Unscreened dataset, range of values for both materials and both comparisons as a function of average slice thickness within the test stack

Figure 7 Core stacks used to produce both same and alternate thickness predictions for PIR boardstock

Figure 8 Math stacks used to produce both same and alternate thickness predictions for XPS boardstock

Figure 9 Profile Mixed stacks used to produce Same Thickness predictions for XPS and PIR boardstock

Figure 10 Math stack used to produce both same and alternate thickness predictions for XPS and PIR boardstock, using only $50 \mathrm{~mm}$ ( 2 in.) products to produce the thin slice stacks.

Figure 11 Typical comparison of thin slice aging curve, 5-year point prediction, and integrated average values [Stovall, 2009]

Figure 12 Worst case comparison of thin slice aging curve, 5-year point prediction, and integrated average values [Stovall, 2009]....

Figure 13 Total error in predicted thermal conductivity due to TDSL, variations among stack types Surface, Core, and Four-slice Mixed.... 28

Figure 14 Total error in predicted thermal conductivity due to TDSL, variations according to product thicknesses from 25 to $100 \mathrm{~mm}$ ( 1 to 4 in.) for core stacks only..................... 29

Figure 15 Specimen extraction from the full size product boards ....................................... 36

Figure 16 TDSL measurement results (Lab D results from specimens prepared for current ruggedness test. For comparison, data from Labs A, B, C are provided from previous slice preparation ruggedness test. "BS14" and "BS10" are bandsaws with 14 and 10 teeth per inch, respectively.)

Figure 17 Homogeneity criteria from ASTM C1303 (2000), showing the 10\% acceptable bounds for an aging slope based upon data from days 1 and 30.

Figure 18 Comparing the $2007 \mathrm{C} 1303$ homogeneity calculation to a proposed simplified version. 


\section{LIST OF TABLES}

Table 1 Experimental parameter classes used in analysis ...................................................... 7

Table 2 Multi-factor analysis results: Type III F-values* ................................................ 14

Table 3 Multi-factor analysis results: Population Marginal Means of "Error"* ..................... 15

Table 6 Evaluating applications for selected test methodology options for PIR boardstock 18

Table 8 Evaluating applications for selected test methodology options for XPS boardstock 20

Table 9 Research Method's 5-Year Prediction of Core Slice Stack [Stovall, 2009] .............. 25

Table 10 Summary of recommendations for both product types included in the ruggedness

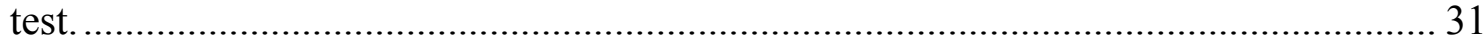

Table 11 PIR dataset results corresponding to recommendations .......................................... 31

Table 12 XPS dataset results corresponding to recommendations ....................................... 31

Table 13 Variables Considered in the Ruggedness Test.................................................... 33

Table 14 Test Schedule of ASTM C518 Thermal Conductivity Measurements ..................... 35

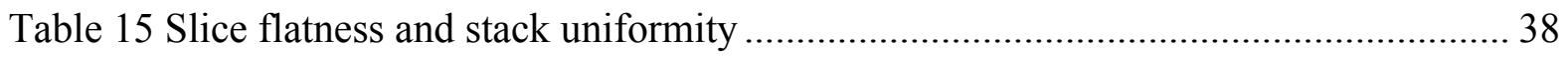

Table 16 Specimen density .............................................................................................. 39

Table 17 Homogeneity Qualification Values ................................................................... 40

Table 18 Alternate Product Thickness Qualification ........................................................... 41

Table 19 Measured TDSL values for a subset of the test specimens...................................... 42 


\section{ACKNOWLEDGMENTS}

This work was supported by the U.S. Department of Energy through the Building Envelope Technology Program under the guidance of Marc Lafrance. Planning support was provided by a committee including Mary Bogdan of Honeywell, Inc., Gary Chu of the Dow Chemical Company, Michel Drouin, Barbara Fabian of Owens Corning Corporation, and David Yarbrough of R\&D Services Inc. Four foam insulation manufacturers have supported the project by supplying foam boards on an ambitious and exacting schedule. Owens Corning provided all the destroyed surface layer measurements. More than a thousand thermal conductivity measurements were made, many on precise time schedules, with help from Phil Childs, and Joanna Miller. The slice preparation is critical to this test method and Jerry Atchley accomplished most of that work with assistance from Dr. Thomas Petrie. 


\title{
EVALUATION OF EXPERIMENTAL PARAMETERS IN THE ACCELERATED AGING OF CLOSED-CELL FOAM INSULATION
}

\author{
Therese Stovall \\ Michael Vanderlan \\ Jerald Atchley
}

\begin{abstract}
The thermal conductivity of many closed-cell foam insulation products changes over time as gases introduced during the production process diffuse out of the cell matrix and atmospheric gases diffuse into the cells. Thin slicing has been shown to be an effective means of accelerating this process in such a way as to produce meaningful results. Efforts to produce a more prescriptive version of the ASTM C1303 standard test method led to the ruggedness test described here. This test program included the aging of full size insulation specimens for five years for direct comparison to the predicted results. Experimental parameters under investigation included: slice thickness, slice origin (at the surface or from the core of the slab), thin slice stack composition, product facings, original product thickness, product density, and product type. The test protocol has been completed and this report provides a detailed evaluation of the impact of the test parameters on the accuracy of the predicted long-term thermal conductivity prediction.
\end{abstract}

\section{INTRODUCTION}

This study has taken place over a six-year time span and two papers have been published with intermediate results.[Stovall and Bogdan, 2007; Stovall, 2009] Some of that information is repeated here in order to provide a complete record of the study. The test protocol is included in its entirety in Appendix A. The early material characterization results are included in Appendix B.

Heat transfer through closed-cell foam insulation occurs via radiation, solid conduction, and gaseous conduction.[Scheutz and Glicksman, 1983] The radiation and solid conduction change little over time, but the gaseous conduction is determined by the composition of the gas mixture within the foam cells. Many closed-cell foam insulation products are produced using a blowing agent, that is, a gas that has a low thermal conductivity relative to that of air. Over time, the cell contents change as atmospheric gases diffuse into the cells and the blowing agent gas(es) diffuse out into the surrounding environment. These changes in the molecular concentration, or partial pressure, of each of the cell gas components are governed by the diffusion coefficient for each gas for the cell wall polymer, the foam thickness, and time. [Isberg, 1988]

Closed-cell foam insulation is used in buildings and appliances; applications with lifetimes ranging from eight to 40 years, or more. The energy efficiency of each application is directly related to the thermal resistance of the foam insulation over that long time period. Accordingly, appliance manufacturers and builders have expressed interest in the long-term thermal resistance values, as opposed to the thermal resistance of new foam. Naturally, users would rather not wait 15 years to obtain these values; so accelerated aging methods were developed. For insulation sheets where the thickness is small relative to the width and length, 
this diffusion process has been shown to follow Fick's Law for one dimensional diffusion. [Kumaran, and Bomberg, 1990; Bomberg, 1990; Edgecombe, 1989; Ball, Healey, and Partington, 1978; Mullenkamp and Johnson, 1983; Booth, 1980; McElroy, et al., 1991; Hoogendoorn, 1994]

Using this approach, cooperative research supported by the Polyisocyanurate Insulation Manufacturers Association and the Department of Energy advanced both the specimen preparation techniques and the data analysis methodology.[Graves, et al.,1995] An ASTM task group was formed and the original version of the ASTM C 1303 test method was published in 1995.[ASTM International (a)]

The flexibility within that test method, although desirable for research purposes, was identified as a hindrance by industry stakeholders, who noted that results can vary depending upon the interpretation, and therefore the implementation, of the version of ASTM C 1303 that was revised and published in 2000. [ASTM International (a)] For example, the thin slice stacks employed by various users have included: (a) core slices only, (b) surface slices only, (c) cross sections of the whole product made up of $10 \mathrm{~mm}$ slices, and (d) cross sections of the whole product where the slice thickness was a function of the whole product thickness. The location of the extracted slices within the original product is an issue because the aging acceleration test protocol is founded upon the physics of one-dimensional gas diffusion through a perfectly homogenous material. However, real foam insulation materials are not perfectly homogenous, and slices taken from different locations in the cross section may exhibit different thermal conductivity and may age at different rates. There may be differences in cell morphology, such as cell size or density, which effect the gas diffusion. There may be adhered or intrinsic facings at the outer surfaces that may be more or less resistant to gas diffusion. No minimum slice thickness was specified in ASTM C 1303-2000, which also contributed to the variability in results.

In 2000, a prescriptive test method based on ASTM C1303, but expanded to include permeably-faced products, was published in Canada (CAN/ULC-S770) and was required for foam insulation products sold in Canada. [Underwriters Laboratory of Canada] This extension of the methodology to permeably-faced products introduced more test practice variants. For example, there was confusion regarding whether a "surface" slice actually included the facer, or if the facer was stripped away before the slice was prepared. An extensive interlaboratory comparison showed that the original CAN/ULC-S770 procedure produced biased results, and that the magnitude of the bias varied according to the material tested and the slice thickness.[Drouin, 2009; Stovall, et al., 2002]

Spurred by these developments, and by the reluctance of the Federal Trade Commission to apply the more flexible ASTM C1303, efforts began in 2003 to produce a prescriptive version of that test method and to expand the scope to include products with permeable facers. During the revision process, questions were raised regarding the applicability of accelerated aged performance values derived from measurements on $50 \mathrm{~mm}$ (2-in.) products to products of other thicknesses. Within C1303 and in this report, this is called an "alternate thickness" or "alternate product thickness" prediction. (Cell morphology differences have been postulated to explain differences in aging behavior for products of differing thicknesses.) This latter issue is especially important considering that the prescriptive option within the most recent ASTM C1303 may be used for product labeling purposes. There were also questions regarding the influence of variations within each material class, such as 
density, manufacturing process, and facer material. Qualification tests were defined in the 2007 version for both product homogeneity and the use of data from alternate product thicknesses (See Appendix C). Pass-fail criteria for these tests were defined subject to revision based upon the results of the ruggedness test reported here.

As a first step in addressing these questions, a theoretical analysis of core and surface slice stacks was made to determine which type of slice would provide a more accurate acceleration of the aging process.[Stovall and Bogdan, 2007] However, considering the many product variations, empirical data was needed to ultimately determine which set of test method parameters would produce results most representative of the aged full thickness products.

A ruggedness test is used to "test the test method". ASTM E1169 provides the definition of a ruggedness test.[ASTM International (e)]

The purpose of a ruggedness test is to identify those factors that strongly influence the measurements provided by a specific test method and to estimate how closely those factors need to be controlled.

Two previous ruggedness tests had addressed questions regarding the cutting methods used to prepare the foam thin slices and the thickness of the destroyed surface layer that results from the cutting process.[ Fabian, et al., 1997; Stovall, 2007] The ruggedness test reported here was organized to answer the questions regarding product differences (class and thickness) and stack composition that were considered to be the most important for the 2007 prescriptive version of ASTM C1303. Another variable, slice thickness (in particular, the differences for slice thicknesses of 8,10 , and $12 \mathrm{~mm}$ ), was examined in a more limited fashion, and was previously considered in the evaluation of CAN/ULC-S770.[Drouin, 2009]

The goals of this ruggedness test were to:

- Identify any difficulties or problems executing the prescriptive method.

- Identify and quantify the impact of sample preparation options, specifically thin slice stack composition, in application to multiple classes of polyisocyanurate foam and extruded polystyrene foam products

- Provide normalized data and statistical analysis sufficient to establish preliminary bias data for the test procedure (within the limitations of the single-lab condition).

- Examine relationships between product characteristics, stack composition, slice thickness, and any 5-year prediction bias via statistical data analysis.

- Examine the efficacy of the homogeneity and alternate product thickness qualification tests and explore modifications to these test criteria if appropriate using statistical analysis of the test data.

\section{TEST EXECUTION}

\subsection{Factors evaluated}

Several points within ASTM E1 169 are pertinent here:[ASTM International (e)] 
.....It is customary to use a "screening type of experiment design which concentrates on examining many first order effects and generally assumes that second order effects such as interactions and curvature are relatively negligible.

...If some effects are identified as statistically significant and practically significant, then the method may have to be modified, or specifications may need to be added for the range of acceptable values of the identified factors.

The factors evaluated in this ruggedness test included

- Product differences (material, class, density, and thickness)

- Stack composition (origin of slices at the surface or core of the original product)

- $\quad$ Slice thickness

- Applicability of accelerated aged performance values derived from measurements on one product thickness to products of other thicknesses for the same material and material class. i.e., "alternate thickness" or "alternate product thickness" predictions

It was anticipated that the criteria for homogeneity and alternate thickness qualifications could be adjusted so that any unacceptable results associated with product differences would be avoided.

In addition to the evaluation of experimental factor effects, this test was designed to provide an estimate of the test method accuracy. For this purpose, full-thickness insulation specimens were aged for five years so that the measured thermal conductivity at that point could be compared to the prediction produced via the accelerated test method.

\subsection{Difficulties encountered}

The test method includes specific requirements for specimen flatness and uniform thickness among the slices within a test stack. This proved to be more difficult to meet for the thinnest $8 \mathrm{~mm}$ slice specimens. Additional rigidity was added to the slicing apparatus and a greater number of slices were produced to provide an adequate number that met the criteria.

The prescriptive method calls for a precise schedule of thermal conductivity measurements, based on the thickness of the product and the thickness of the thin slice. The calculations that establish this schedule of measurements are somewhat complex and errors were made in defining those times for the initial specimens. The task group discussed this issue and the standard was modified to include example calculations.

Some test measurement schedules required trips to the laboratory on holidays or in the wee hours of the morning. The task group discussed this issue and the standard was modified to permit a limited amount of interpolation so that test measurements could be made on a more convenient schedule.

\subsection{Stack types}

Three of the five stack types reported here match the stack types described in the C1303 prescriptive procedure. The "Surface" stack is a simple stack of surface slices, all with surface side up, as shown on the left in Figure 1. The surface stack will include the effect of any diffusion resistance provided by a densified surface or a facer, although each surface slice also includes an opposite cut surface without this extra diffusion resistance. The "Core" stack consists of only slices taken from the core of the product, that is, excluding the 
surfaces. The core stack is composed of that portion of the foam that is relatively undisturbed by any diffusion that occurs between the time the foam is manufactured and when the thin slices are prepared. The "Profile Mixed" stack, shown on the right in Fig. 1, is a replication of an actual cross product section with two surface sides out and enough cores to make the stack height equal to the original product thickness, minus the thickness of the material destroyed during the slicing process. Note that for a $25 \mathrm{~mm}$ (1 inch) product, the surface and profile mixed stacks are composed of the same slices, although the orientation of the slices would differ (see Fig. 1). Another version of the mixed stack was also tested, called here a "Four-slice Mixed" stack. This consisted of two outward facing surface slices with two core slices in the center. For the 50-mm (2 inch) products, the four-slice mixed stack is the same as the profile mixed stack. An additional stack type is a mathematical derivation, using the standard series resistance expression to weight the measured values from the core and surface stacks to represent the overall product structure, as shown in Eq 1 and 2.

$$
\begin{gathered}
R_{\text {total }}=\frac{L_{\text {product }}}{k_{\text {effective }}}=\sum R=\sum \frac{\Delta x}{k}=\left(\frac{2 L_{\text {surface }}}{k_{\text {surface }}}\right)+\left(\frac{L_{\text {product }}-2 L_{\text {surface }}}{k_{\text {core }}}\right) \\
\text { for } F_{\text {surface }}=\frac{2 L_{\text {surface }}}{L_{\text {product }}}, \text { then } \frac{1}{k_{\text {effective }}}=\left(\frac{F_{\text {surface }}}{k_{\text {surface }}}\right)+\left(\frac{1-F_{\text {surface }}}{k_{\text {core }}}\right)
\end{gathered}
$$

where:
$\mathrm{R}=$ Thermal resistance, $\mathrm{K} / \mathrm{W}$
$\mathrm{L}=\quad$ Thickness, $\mathrm{m}$
$\mathrm{k}=$ Thermal conductivity, $\mathrm{W} / \mathrm{m}-\mathrm{K}$
$\mathrm{F}=$ Fraction
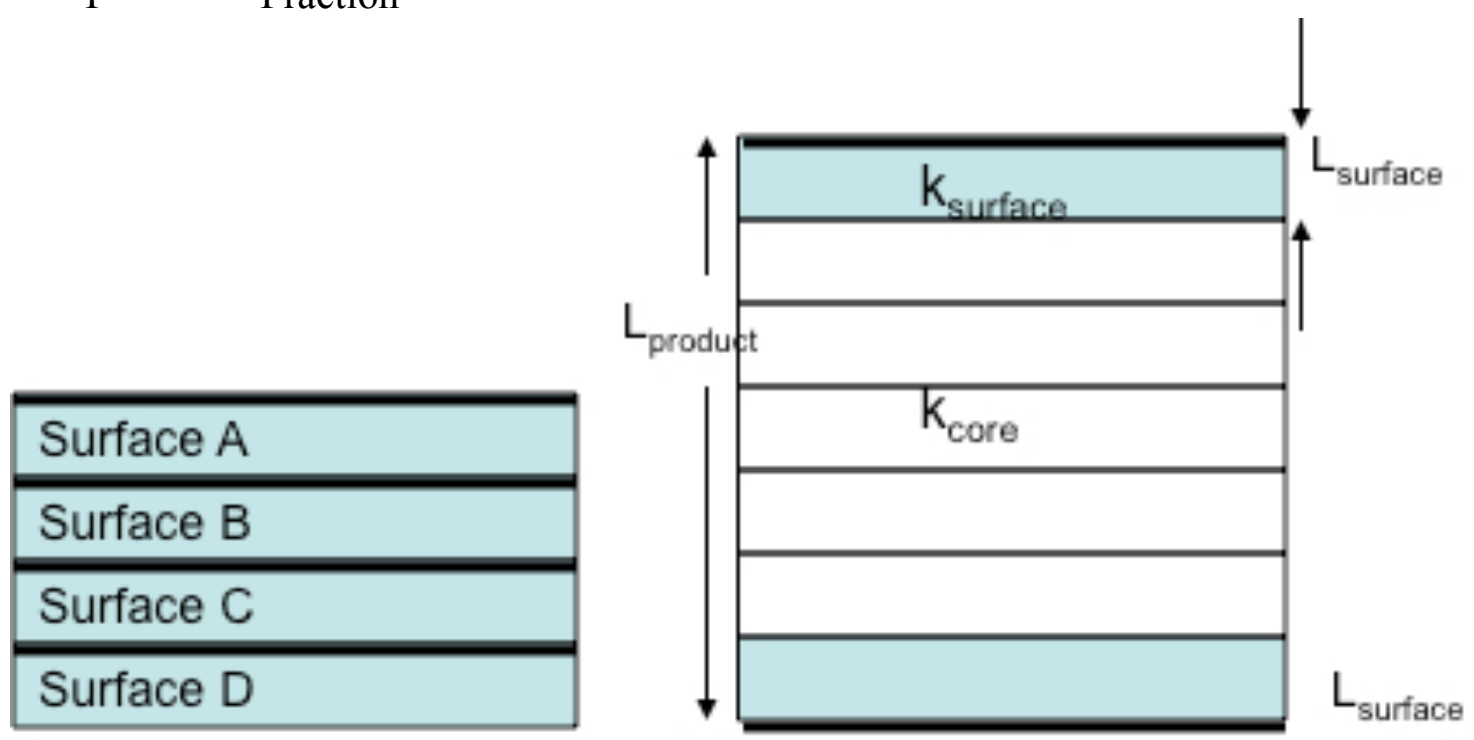

Figure 1 Diagram of stack design, Surface stack (left), Profile Mixed stack (right)

\subsection{Thermal conductivity measurements}

During the course of this project, more than 1,000 ASTM C518 thermal conductivity measurements were made.[ASTM International (c)] About 600 thin slice thermal conductivity measurements met the requirements of the C1303 Prescriptive Method. The 
other measurements were used to examine the application of the C1303 Research Method. After interpolation was added to the prescriptive method, some of these additional data values were used for interpolation purposes and the resulting values included within the prescriptive method evaluation. For the data used in the five-year comparison, there were 214 thermal conductivity measurements for slice stacks and 100 for full thickness specimens. The thermal conductivity of all 20 full thickness products was measured.

All the thermal conductivity measurements were made on one of four heat flux meter apparatus, regularly control-charted using the same stable specimen. For most materials, there were at least three full thickness measurements made after five years of aging. For all full thickness materials, at least one measurement was made using a $600 \times 600 \mathrm{~mm}(24 \times 24$ in.) specimen in a Fox 605 heat flux meter apparatus with a $20 \times 20 \mathrm{~mm}(8 \times 8$ inch) metering area. For 25- and 50-mm thick specimens, that test specimen was then cut into four equal pieces so that multiple measurements could also be made in a Fox 304 heat flux meter apparatus with a $10 \times 10 \mathrm{~mm}(4 \times 4 \mathrm{inch})$ metering area. That same Fox machine was used for most of the thin slice measurements.

\section{ANALYSIS}

\subsection{Data organization}

In order to produce a robust statistical analysis, every individual prediction was compared to every corresponding full thickness measurement. That is, the value predicted for five years from each of the five thin slice stacks was compared to each of the replicate full thickness measurements individually. In the cases where replicate measurements were available for the thin slice stacks, each predicted value was individually compared to the full thickness five-year measurement. The comparisons include predictions made using original specimens from both the same product thickness and from other product thicknesses. The resulting data set therefore reflects unbalanced multiple effects. The final dataset contains a family of multiple predicted values for each measured full thickness value, resulting in a total of $\sim 1,300$ observations. The error, or difference between the predicted value and the measured value as defined in Eq. 3, was calculated for each observation.

$$
\text { Error }(\%)=\frac{\left(k_{\text {Predicted }}-k_{\text {Full Thickness }}\right)}{k_{\text {Full Thickness }}} \times 100 \%
$$

Where:

$\mathrm{k}=\quad$ Thermal conductivity, $\mathrm{W} / \mathrm{m}-\mathrm{K}$

Using this definition:

- A positive error indicates the predicted thermal conductivity was too high - and therefore the predicted thermal resistance was too low.

- A negative error indicates the predicted thermal conductivity was too low-and therefore the predicted thermal resistance was too high.

The data set also included corresponding values for multiple possible effect classes. Some of these classes are associated with possible variations in the test methodology, such as stack type, whether or not predictions can be made using products of alternate thickness, or slice thickness. Other classes are useful in examining whether the test method accuracy 
varies between different applications, that is, whether it works equally well for different material varieties or products from different manufacturers. A few of the classes represent potential screening variables, including those defined as qualification screens in the 2010 version of C1303. Finally, a few variables were considered as continuous numerical values, rather than as classes of distinct values. A partial listing of the classes included in the data set are summarized in Table 1.

\section{Table 1 Experimental parameter classes used in analysis}

\begin{tabular}{|c|c|}
\hline Classes & Possible values \\
\hline \multicolumn{2}{|r|}{ Methodology Classes } \\
\hline Product thickness & $25,50,100 \mathrm{~mm}$ (note $75 \mathrm{~mm}$ included in $100 \mathrm{~mm}$ class) \\
\hline Original product thickness & Applies when alternates product thickness is used to make the prediction \\
\hline Stack type & $\begin{array}{l}\text { Surface, Core, Four-slice mixed, Cross-section mixed, and Mathematically } \\
\text { constructed }(1,2,3,4 \text {, or } 5)\end{array}$ \\
\hline Machine Comparison & $\begin{array}{l}\text { Same or Different, whether the heat flux meter apparatus used to measure the } \\
\text { full thickness specimen was the same as the one used to measure the thin slice } \\
\text { stack that produced the predicted value }\end{array}$ \\
\hline Thickness Comparison & $\begin{array}{l}\text { Same or Alternate, whether the original specimen used to produce the } \\
\text { prediction was of the same thickness as the full thickness specimen }\end{array}$ \\
\hline Slice thickness & 8,10, or $12 \mathrm{~mm}$ \\
\hline \multicolumn{2}{|r|}{ Application Classes } \\
\hline Variety & Class 1 or Class 2 for PIR, Low or High density for XPX \\
\hline Manufacturer & Four included, 2 each for PIR and XPS \\
\hline \multicolumn{2}{|r|}{ Screening Classes } \\
\hline Homogeneity & $\begin{array}{l}\text { Multiple breakpoint levels were considered. Multiple definitions were } \\
\text { considered. }\end{array}$ \\
\hline $\begin{array}{l}\text { Alternate thickness thermal } \\
\text { conductivity equivalence }\end{array}$ & $\begin{array}{l}\text { Multiple breakpoint levels were considered. Multiple definitions were } \\
\text { considered. }\end{array}$ \\
\hline $\begin{array}{l}\text { Alternate thickness aging } \\
\text { equivalence }\end{array}$ & Multiple breakpoint levels were considered \\
\hline Test Duration & Multiple breakpoint levels were considered \\
\hline \multicolumn{2}{|r|}{ Continuous Variables } \\
\hline Test Duration & (Determined by a combination of slice thickness and product thickness) \\
\hline \multicolumn{2}{|l|}{ Slice thickness } \\
\hline Homogeneity value & See Appendix C \\
\hline $\begin{array}{l}\text { Alternate thickness thermal } \\
\text { conductivity equivalence }\end{array}$ & See Appendix C \\
\hline $\begin{array}{l}\text { Alternate thickness aging } \\
\text { equivalence }\end{array}$ & See Appendix C \\
\hline
\end{tabular}

\subsection{Methodology}

The first stage of the analysis was to examine the results using a series of scatter plots. This provided a rough idea of the factor relationships and was useful in devising possible class breakpoints. Next, general linear models were used to identify which experimental factors were most important. Finally, histograms were used to examine the impact of potential test methodology selections and screening factors on the dataset.

Statistical analysis was used to compare the response, or dependent variable, to the independent model variables. A general linear model with a continuous response variable, error, was combined with an analysis of covariance (ANCOVA) using multiple class variables (such as stack type or material type). The population marginal means (PMM, also 
called LSMeans in SAS) were calculated to get a feel for the influence of each parameter in the model.[SAS Institute, Inc., 2007] The PMM is a function of both the structure of the parametric model and the data.[Searle, Speed and Milliken (1980)] For example, the PMM for the effect of a core stack will be different depending upon which other effects were included in the model. If the model looked at the effects of stack type (surface, core, mixed, profile, and math) and product variation (Class1 and Class 2), the PMM for core stack effect would be the average of two other averages. The first average would be for all core stacks of products in Class 1 and the second average would be for all core stacks of products in Class 2. If the data set were perfectly balanced, there would be an equal number of test data points in each of those averages and the overall mean for core stacks would equal the PMM for core stacks. However, in an unbalanced data set, there will be more data points in one class than in the other. In that case, the PMM serves to 'balance' an unbalanced data set. Note that the PMM can only be calculated if there is at least one observation for each possible combination of the effects in the model.

The analysis also produces the F-statistics, the explained variance divided by the unexplained variance as shown in Eq. 4, which is useful in determining which experimental parameters are most important within the test protocol. The Type III ANOVA used here is unbiased, that is, the results are independent of the order in which the class variables are considered.[Gill, 2001 and Pasta, 2011] Also, the Bonferroni t-test form was used to adjust for the large number of parameters in the model.[Miller, 1981] This form of t-test provides a more rigorous test of significance for the influence of each parameter in the model.

$$
F=\frac{\text { explained variance }}{\text { unexplained variance }}
$$

\section{PRESCRIPTIVE TEST METHOD RESULTS}

\subsection{Overview}

The raw data are summarized in Figure 2 to Figure 6. Figure 2 shows that the bulk of the predictions are within $\pm 5 \%$ of the full thickness values, but there are also some outliers. In Figure 3, the same dataset is broken down further to show the impact of stack type and whether predictions are based upon slices taken from the same product thickness or an alternate product thickness. Looking at both these figures, it is apparent that some sort of screening is needed for the alternate thickness predictions. Further, it appears that surface stacks would not be a good choice for PIR, and that core stacks would not be the best choice for XPS. 


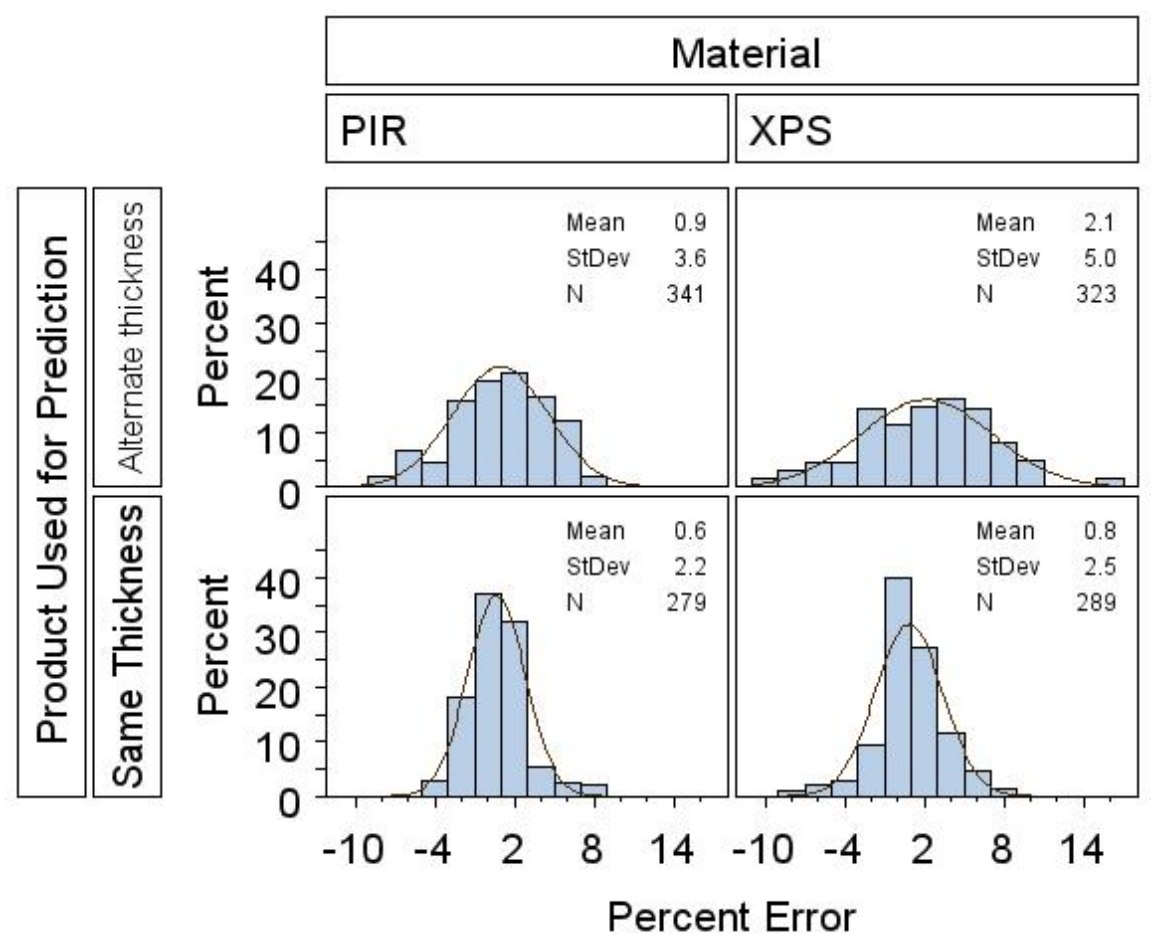

Figure 2 Unscreened dataset, range of values for PIR and XPS for alternate thickness comparisons and same thickness comparisons

Because the aging acceleration is based upon Fick's Law for one-dimensional diffusion, which holds true for homogenous materials, homogeneity screening had been included in all versions of ASTM C1303 through 2012, as described in Appendix C. The earliest form of this was based on a qualitative examination of the aging data, looking at the slope of the thermal conductivity vs. time data gathered during the early stages of thin slice aging. This was transformed into a quantitative process when the prescriptive form of the test procedure was developed, using thin slice thermal conductivity values taken after aging periods of 24 $\mathrm{h} / \mathrm{cm}^{2}$ and 30 days $/ \mathrm{cm}^{2}$. (The quantitative evaluation is shown in Appendix C, Eq. 11.) The horizontal shaded area, with errors $\sim-3$ to $3 \%$, in Figure 4 shows that this quantitative criterion seems to have little correlation with the accuracy of the predicted thermal conductivity. The $2010 \mathrm{C} 1303$ criteria limited the application of the test method to products with homogeneity between 90 and $110 \%$. In fact, the values were all within 92 to $100 \%$ for the XPS and PIR products tested. Figure 4 shows that tightening up that requirement (see the vertical shaded area with homogeneity between 95 and $100 \%$ ) would not be an effective way to improve the standard. An alternative form of the homogeneity criteria was developed during this study. This simplified version uses the 30 day data alone, and would therefore simplify both the calculations and the test execution. This simplified version is also described in Appendix C and the results, restricted to the Math Stack, are shown in Figure 5. The simplified homogeneity measure spread the values out over a broader spectrum, from $\sim 85$ to $110 \%$ for this dataset. Just as with the aging homogeneity shown in Figure 4, there was no relationship between this measure and the accuracy of the predictions for the products tested here. However, if some form of homogeneity qualification is maintained in the C1303 test 
methodology to screen out products with extreme variations in homogeneity, this simpler measure may be useful.

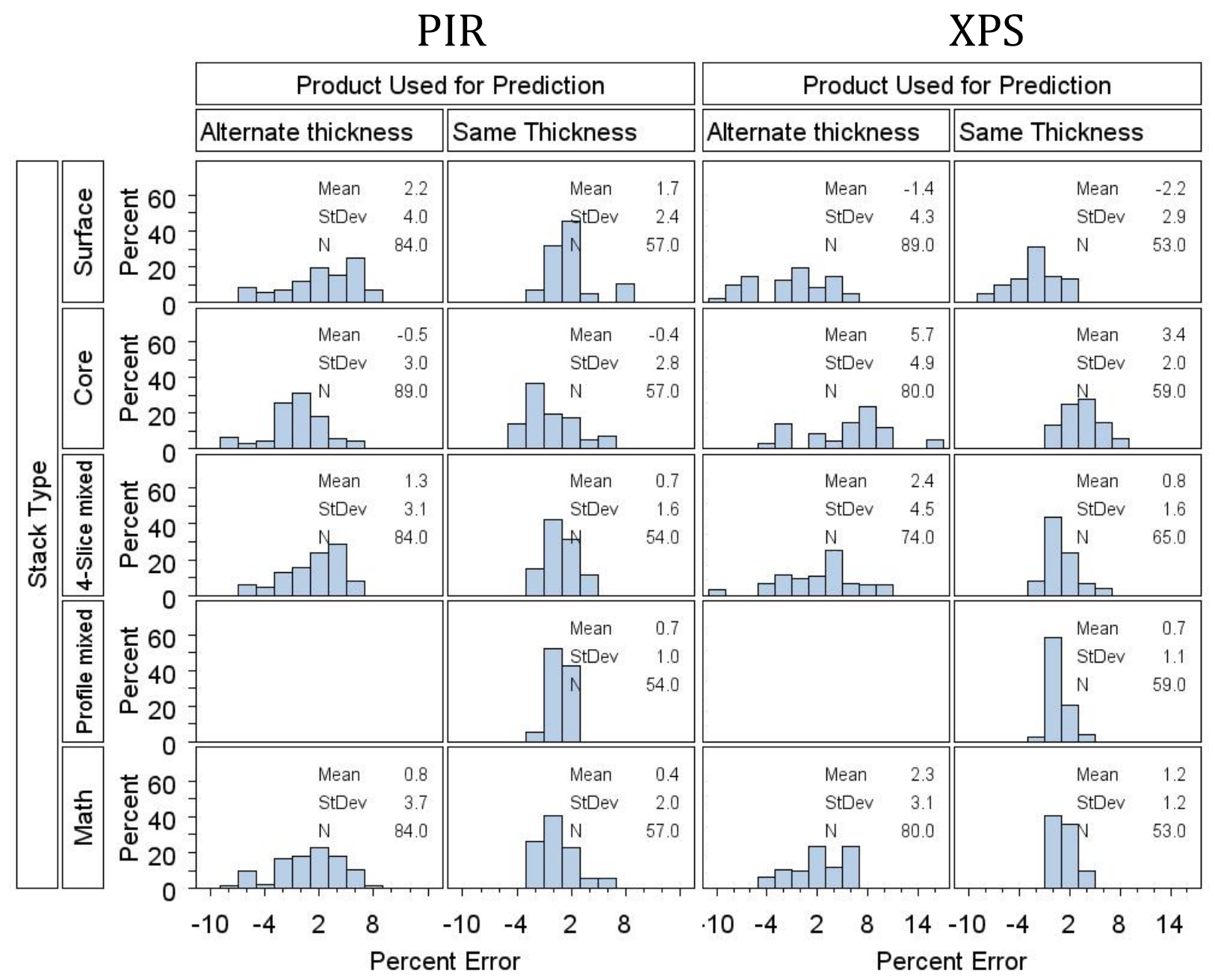

Figure 3 Unscreened dataset, range of values for PIR and XPS for both comparisons (same and alternate thickness) for five stack types.

The test plan called for most of the test slices to be $10 \mathrm{~mm}$ thick, with some at 8 and others at $12 \mathrm{~mm}$ to evaluate the impact of that test parameter. Previous unpublished work done during the development of CAN/ULC S770 has shown that it is difficult to maintain the necessary slice flatness, that is, the uniformity of the slice thickness, for slice thicknesses smaller than $8 \mathrm{~mm}$. Figure 6 shows that the actual execution represents a more continuous spectrum of slice thickness. Therefore statistical models were explored to consider slice thickness both as a continuous numerical value and as a class variable with three levels. 


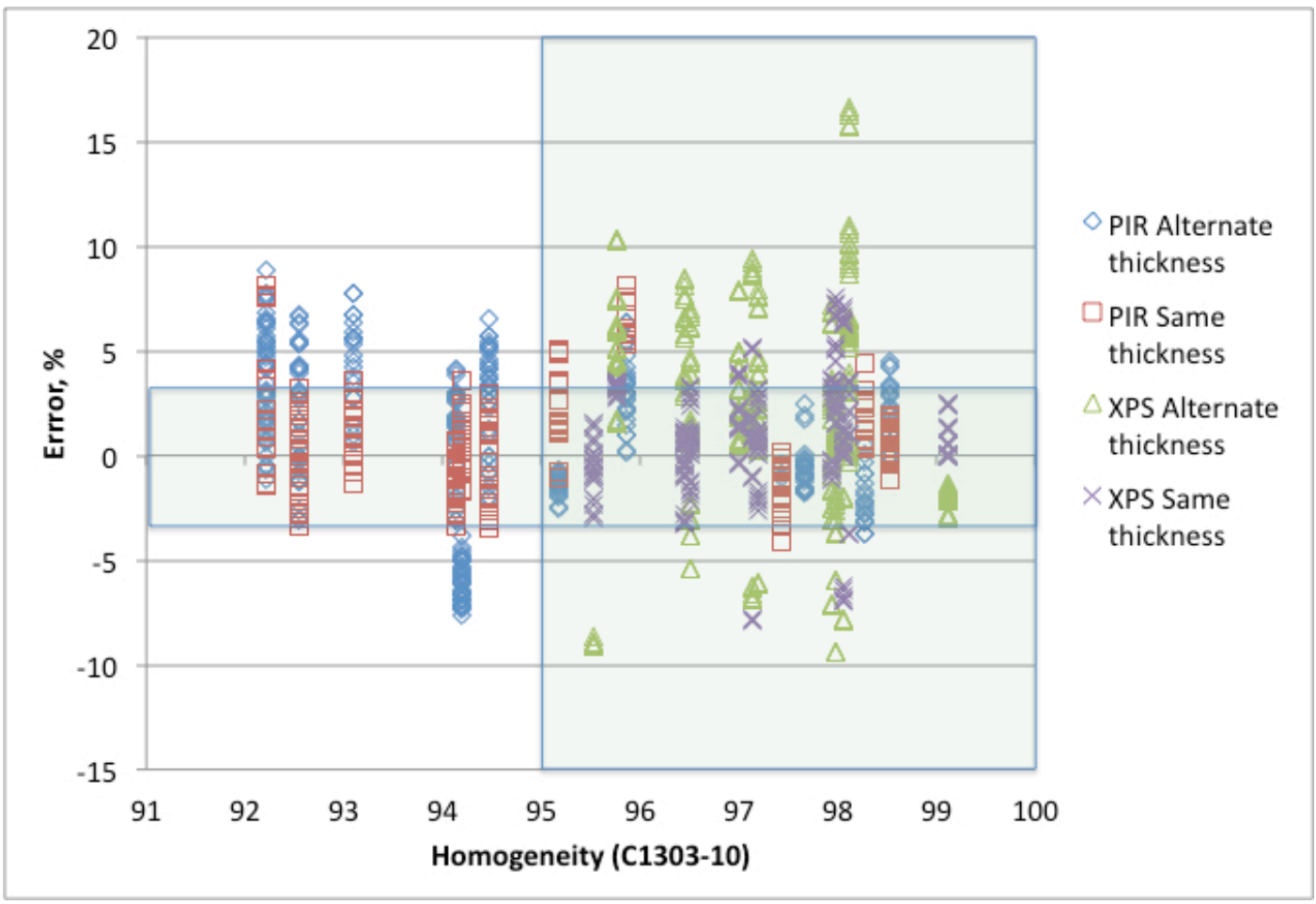

Figure 4 Unscreened dataset, looking at homogeneity based on aging as defined in the 2010 version of ASTM C1303. Shaded area represents "better" homogeneity.

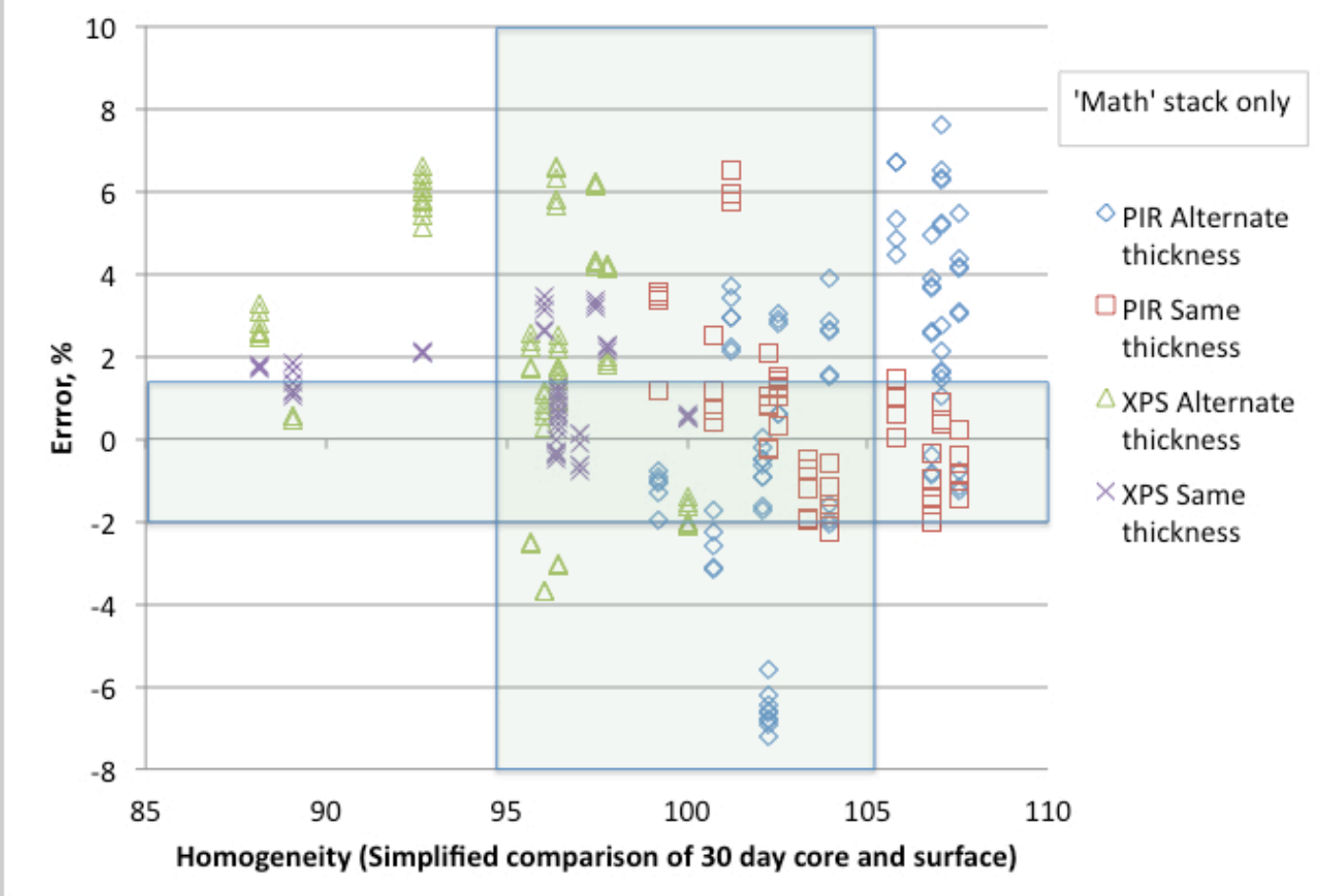

Figure 5 Dataset confined to mathematical stack only, looking at proposed "simplified" homogeneity measure based on a comparison of core and surface thermal conductivity at 30 days $/ \mathrm{cm}^{2}$. 


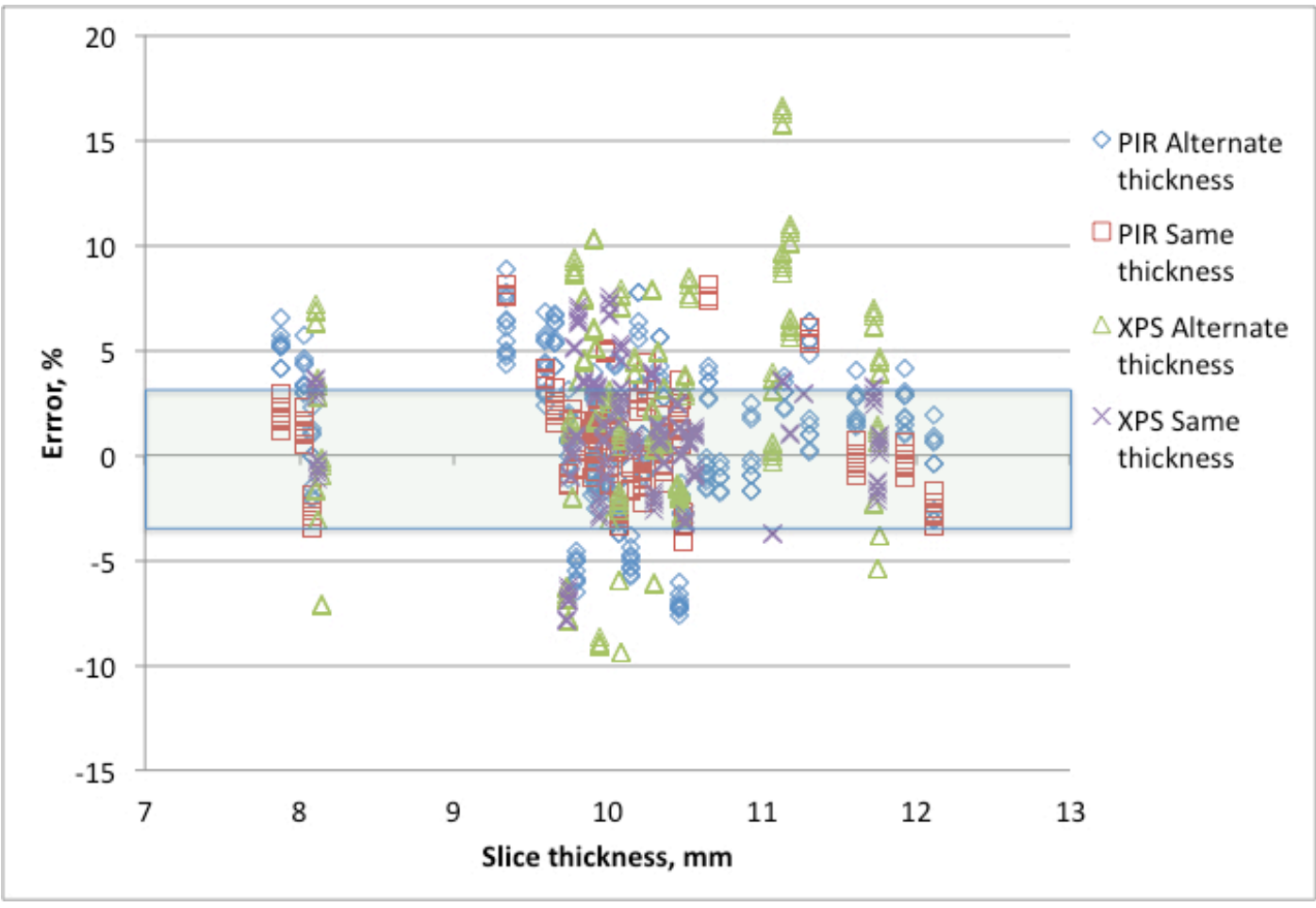

Figure 6 Unscreened dataset, range of values for both materials and both comparisons as a function of average slice thickness within the test stack

\subsection{General Linear Model Analyses}

Based upon the scatter plot examination, the PIR and XPS were treated separately for the general linear model analyses, as were the alternate product thickness predictions and the same product thickness predictions. Before conducting the linear model analysis, the distributions of the results for these four groupings of interest were evaluated as shown in Figure 2. The distributions are sufficiently close to a normal distribution to justify the linear model approach.

A large number of general linear model constructions were then tested. In the initial examination, all potential classification variables were used in the model. Those variables shown to be least significant to the model were eliminated one at a time. Interactions of variables were then examined for significance.

Table 2 and Table 3 summarize the results of the statistical analysis. Only those class variables that were significant at the 0.99 level, as determined by the t-test, are included in this table. The original product thickness, i.e., the thickness of the product used to produce the thin slices, appeared in every statistically significant comparison, and had a significant impact for most, as indicated by the large F-values. (Note that for Same Thickness comparisons, the product thickness is equal to the original product thickness.) Manufacturer showed little to no effect on its own, but for alternate product thickness comparisons, the combination of manufacturer and product thickness was important. Homogeneity and alternate product thickness thermal conductivity screens were statistically significant for PIR (not for XPS), but the population marginal mean values in Table 3 indicate they may be of 
little value for our purposes. Some variables were confounded by their close association with other variables. For example, the test duration for all 75-100 mm (3-4 in.) products was less than 40 days, so those two factors were ineffective when placed in the same model.

Two experimental factors were of special interest, stack type and slice thickness. Stack type plays a critical role in the test method accuracy for both of these two materials. Slice thicknesses between 8 to $12 \mathrm{~mm}$ were statistically significant in only one of the final models, that for PIR predictions made from the same product thickness.

\subsection{Test Methodology evaluation for two materials}

The ultimate goal of the analyses is to evaluate which test methodology options produce the most accurate predictions of long-term thermal conductivity, and to evaluate whether these options work equally well for different product classes and for products from different manufacturers. The general linear model results were used to guide the evaluation for both products.

\subsubsection{PIR, Alternate and same thickness predictions}

The Population Marginal Means values for PIR indicate that: (1) the core and math stacks produce more accurate results; (2) using $100 \mathrm{~mm}$ (4 in.) products produces large errors, even when used to make predictions for products of that same thickness; (3) the homogeneity and alternate thickness thermal conductivity screening criteria produce results that are either insignificantly different, or actually contrary to the desired goal (that is, materials that show 'better' criteria produced greater errors); and (4) results for slice thickness, significant only for same-thickness predictions) were the same for 8 and $10 \mathrm{~mm}$ slices and much worse for $12 \mathrm{~mm}$ slice thickness, which is contrary to expectations based upon the relative magnitude of the errors introduced by TDSL as described in Section 5.2.

While the Population Marginal Means values correct for the unbalanced nature of the dataset, the means and standard deviations for the actual test values support these conclusions, as shown in Table 4, except that the results for $12 \mathrm{~mm}$ slices appear to be much closer to the $10 \mathrm{~mm}$ slices. Also, the profile mixed stack produced good results for the same thickness prediction.

Using these trends to guide the selection of test methodology options by deleting the surface stack and the predictions based on the original product thickness of $100 \mathrm{~mm}$ (4-in.), the means for subsets of the actual test values are shown in Table 5. Considering the means and standard deviations, the most robust approach to the test methodology would appear to be to use core stacks from $50 \mathrm{~mm}$ ( 2 in.) products to produce alternate thickness predictions and to use profile mixed stacks to produce same thickness predictions. The math stack also offers reasonable results for same thickness and for alternate thickness if combined with the alternate thickness qualification criteria. 
Table 2 Multi-factor analysis results: Type III F-values*

\begin{tabular}{|c|c|c|c|c|}
\hline & \multicolumn{2}{|c|}{ Alternate Thickness } & \multicolumn{2}{|c|}{ Same Thickness } \\
\hline & PIR & XPS & PIR & XPS \\
\hline Correlation coefficient, $\mathrm{R}^{2}$ & .84 & 0.86 & .55 & .63 \\
\hline $\begin{array}{l}\text { Simplified homogeneity, screened at } 94-106 \% \\
\text { (screening candidate) }\end{array}$ & 46 & & 42 & \\
\hline $\begin{array}{l}\text { Averaged Lambda, screened at 95-105\% (screening } \\
\text { candidate) }\end{array}$ & 99 & & & \\
\hline $\begin{array}{l}\text { Original product thickness (source of slices) } \\
\text { (methodology evaluation) }\end{array}$ & 112 & 162 & & \\
\hline Stack (methodology evaluation) & 67 & 165 & 16 & 90 \\
\hline $\begin{array}{l}\text { Product thickness (full thickness compared to } \\
\text { slices) (application factor) }\end{array}$ & 10 & 222 & 103 & 13 \\
\hline Manufacturer (application factor) & & 5 & & \\
\hline $\begin{array}{l}\text { Product thickness*manufacturer (application } \\
\text { factor) }\end{array}$ & 179 & 77 & & \\
\hline $\begin{array}{l}\text { Simplified homogeneity*Average lambda screens } \\
\text { (screening candidate) }\end{array}$ & 33 & & & \\
\hline $\begin{array}{l}\text { Slice thickness class }(8,10,12 \mathrm{~mm}) \text { (methodology } \\
\text { evaluation) }\end{array}$ & & & 26 & \\
\hline Variety (application factor) & & & & 54 \\
\hline Product thickness* variety (application factor) & & & 36 & 15 \\
\hline
\end{tabular}


Table 3 Multi-factor analysis results: Population Marginal Means of "Error"*

\begin{tabular}{|c|c|c|c|c|c|}
\hline \multirow{3}{*}{ Class } & \multirow{3}{*}{ Class Value } & \multicolumn{4}{|c|}{ Error (Standard deviation of error), \% } \\
\hline & & \multicolumn{2}{|c|}{ Alternate Thickness } & \multicolumn{2}{|c|}{ Same Thickness } \\
\hline & & PIR & XPS & PIR & XPS \\
\hline \multirow[t]{5}{*}{ Stack } & Surface & $2.2(0.2)$ & $-1.0(0.2)$ & $1.6(0.2)$ & $-2.2(0.2)$ \\
\hline & Core & $-0.8(0.2)$ & $5.5(0.2)$ & $-0.5(0.2)$ & $3.4(0.2)$ \\
\hline & 4-Slice Mixed & $1.5(0.2)$ & $2.4(0.2)$ & $0.9(0.2)$ & $0.8(0.2)$ \\
\hline & Profile Mixed & NA & NA & $0.9(0.2)$ & $0.7(0.2)$ \\
\hline & Math & $0.9(0.2)$ & $2.1(0.2)$ & $\begin{array}{l}0.3(0.2) \\
89 \% \mathrm{CL}\end{array}$ & $1.1(0.2)$ \\
\hline \multirow{3}{*}{$\begin{array}{l}\text { Slice origin } \\
\text { product thickness }\end{array}$} & $25 \mathrm{~mm}$ (1 in.) & $-1.0(0.3)$ & Not sig. & & \\
\hline & $50 \mathrm{~mm}$ (2 in.) & $0.6(0.2)$ & $.8(0.2)$ & & \\
\hline & 75-100 mm (3 - 4 in.) & $3.5(0.2)$ & $4.9(0.2)$ & & \\
\hline \multirow{3}{*}{$\begin{array}{l}\text { Product thickness, } \\
\text { Class } 1 \text { for PIR and } \\
\text { standard density for } \\
\text { XPS (other variations } \\
\text { not significant) }\end{array}$} & 1 inch & & & $-2.1(0.3)$ & $2.4(0.2)$ \\
\hline & 2 inch & & & $2.4(0.4)$ & $0.7(0.2)$ \\
\hline & 3 or 4 inch & & & $5.0(0.3)$ & $2.3(0.3)$ \\
\hline \multirow{2}{*}{$\begin{array}{l}\text { Simple 30-day } \\
\text { homogeneity screen }\end{array}$} & Pass & & & $1.7(0.2)$ & \\
\hline & Fail & & & $-2.3(0.5)$ & \\
\hline \multirow{4}{*}{$\begin{array}{l}\text { Simple } 30 \text {-day } \\
\text { homogeneity } \\
\text { screen/Alternate } \\
\text { thermal conductivity } \\
\text { screen } 95 \text { to } 105 \%\end{array}$} & Fail/fail & $0.8(0.3)$ & & & \\
\hline & Fail/pass & $1.8(0.2)$ & & & \\
\hline & Pass/Fail & $-2.7(0.4)$ & & & \\
\hline & Pass/Pass & $1.3(0.1)$ & & & \\
\hline \multirow{3}{*}{$\begin{array}{l}\text { Nominal slice } \\
\text { thickness, mm }\end{array}$} & 8 & & & $1.3(0.3)$ & \\
\hline & 10 & & & $1.2(0.1)$ & \\
\hline & 12 & & & $-3.9(0.7)$ & \\
\hline
\end{tabular}


Several application factors were also statistically significant in the general linear models. For alternate thickness predictions, the combination of product thickness and manufacturer was the most important factor in the model, based on the Type III F-values in Table 3. Similarly, the combination of product thickness and variety 1 was the third most important factor for same thickness predictions. The impact of the selected test methodology options for these application factors are shown in Table 6.

Table 4 PIR dataset single-effect results for Error (\%) for test methodology and screening criteria classes

\begin{tabular}{|c|c|c|c|c|c|c|}
\hline & \multicolumn{3}{|c|}{ Alternate thickness } & \multicolumn{3}{|c|}{ Same thickness } \\
\hline & Mean & $\begin{array}{l}\text { Standard } \\
\text { Dev. }\end{array}$ & $\begin{array}{l}\text { No. of } \\
\text { comparisons }\end{array}$ & Mean & $\begin{array}{l}\text { Standard } \\
\text { Dev. }\end{array}$ & $\begin{array}{l}\text { No. of } \\
\text { comparisons }\end{array}$ \\
\hline \multicolumn{7}{|c|}{$\begin{array}{l}\text { Original product } \\
\text { thickness, mm (in.) }\end{array}$} \\
\hline $25(1)$ & -2.7 & 3.6 & 79 & 0.4 & 1.7 & 115 \\
\hline $50(2)$ & 1.4 & 2.8 & 185 & 0.2 & 1.8 & 140 \\
\hline $100(3)$ & 3.5 & 2.3 & 77 & 4.0 & 3.2 & 24 \\
\hline \multicolumn{7}{|c|}{$\begin{array}{l}\text { Alternate thickness } \\
\text { criteria } B^{*}\end{array}$} \\
\hline Fail & -0.3 & 5.4 & 84 & & & \\
\hline Pass & 1.3 & 2.7 & 257 & & & \\
\hline \multicolumn{7}{|l|}{ Stack type } \\
\hline Surface & 2.2 & 4.0 & 84 & 1.7 & 2.4 & 57 \\
\hline Core & -0.5 & 3.0 & 89 & -0.4 & 2.8 & 57 \\
\hline 4-Slice Mixed & 1.3 & 3.1 & 84 & 0.7 & 1.6 & 54 \\
\hline Profile Mixed & & & & 0.7 & 1.0 & 54 \\
\hline Math & 0.8 & 3.7 & 84 & 0.4 & 2.0 & 57 \\
\hline \multicolumn{7}{|l|}{$\begin{array}{l}\text { Simplified } \\
\text { homogeneity } \\
\text { criteria*** }\end{array}$} \\
\hline Fail & 3.0 & 2.7 & 120 & 0.5 & 2.4 & 75 \\
\hline Pass & -0.2 & 3.5 & 221 & 0.7 & 2.1 & 204 \\
\hline \multicolumn{7}{|l|}{$\begin{array}{l}\text { Nominal slice } \\
\text { thickness, } \mathbf{m m}\end{array}$} \\
\hline 8 & & & & 0.1 & 1.9 & 30 \\
\hline 10 & & & & 0.9 & 2.2 & 219 \\
\hline 12 & & & & -1.0 & 1.1 & 30 \\
\hline \multicolumn{7}{|c|}{$\begin{array}{l}\text { *Alternate thickness criteria B is based on taking the average of the thermal conductivity } \\
\text { comparisons (core to core and surface to surface) at } 30 \text { days, with a } 95 \text { to } 105 \% \text { passing criteria. } \\
* * \text { Simplified homogeneity criteria is based on comparing the core to surface thermal conductivity at } \\
30 \text { days, with a } 94 \text { to } 106 \% \text { passing criteria. }\end{array}$} \\
\hline
\end{tabular}

1 Variety indicates one of two Classes for PIR and one of two densities for XPS 
Table 5 PIR dataset multiple-effect results for Error (\%) for test methodology and screening criteria classes

\begin{tabular}{|c|c|c|c|c|c|c|c|c|}
\hline \multirow{2}{*}{$\begin{array}{l}\text { Original } \\
\text { product } \\
\text { thickness, } \\
\text { mm (in.) }\end{array}$} & \multirow[b]{2}{*}{ Stack type } & \multirow[b]{2}{*}{$\begin{array}{l}\text { Alternate } \\
\text { thickness } \\
\text { criteria B* }\end{array}$} & \multicolumn{3}{|c|}{ Alternate thickness } & \multicolumn{3}{|c|}{ Same thickness } \\
\hline & & & Error & $\begin{array}{l}\text { Std. } \\
\text { Dev. }\end{array}$ & $\begin{array}{l}\text { No.of } \\
\text { com- } \\
\text { parisons }\end{array}$ & Mean & $\begin{array}{l}\text { Std. } \\
\text { Dev. }\end{array}$ & $\begin{array}{l}\text { No. of } \\
\text { com- } \\
\text { parisons }\end{array}$ \\
\hline \multirow{7}{*}{$25(1)$} & \multirow{2}{*}{ Core } & Pass & 0.1 & 2.6 & 10 & -0.1 & 2.4 & 23 \\
\hline & & Fail & -7.0 & 0.5 & 9 & & & \\
\hline & \multirow{2}{*}{ 4-Slice Mixed } & Pass & 1.0 & 2.2 & 13 & 0.4 & 2.0 & 23 \\
\hline & & Fail & -5.0 & 0.6 & 9 & & & \\
\hline & Profile Mixed & & \multicolumn{3}{|l|}{$\mathrm{NA}^{* *}$} & 0.6 & 1.1 & 23 \\
\hline & \multirow{2}{*}{ Math } & Pass & -0.3 & 2.6 & 10 & 0.5 & 1.3 & 23 \\
\hline & & Fail & -6.6 & 0.5 & 9 & & & \\
\hline \multirow{7}{*}{$50(2)$} & \multirow{2}{*}{ Core } & Pass & -0.6 & 1.6 & 41 & -1.1 & 2.7 & 28 \\
\hline & & Fail & -0.3 & 0.9 & 6 & & & \\
\hline & \multirow{2}{*}{ 4-Slice Mixed } & Pass & 1.6 & 2.5 & 38 & & & \\
\hline & & Fail & 2.6 & 0.9 & 6 & & & \\
\hline & Profile Mixed & & \multicolumn{3}{|l|}{$\mathrm{NA}^{* *}$} & 0.6 & 0.9 & 28 \\
\hline & \multirow{2}{*}{ Math } & Pass & 1.0 & 2.6 & 41 & -0.2 & 1.6 & 28 \\
\hline & & Fail & 4.0 & 0.9 & 6 & \multicolumn{3}{|l|}{-0.2} \\
\hline
\end{tabular}


Table 6 Evaluating applications for selected test methodology options for PIR boardstock, Error (\%)

\begin{tabular}{|c|c|c|c|c|}
\hline & $\begin{array}{l}\text { Product thickness, } \\
\text { mm (in.) }\end{array}$ & Mean & $\begin{array}{l}\text { Standard } \\
\text { Deviation }\end{array}$ & $\begin{array}{l}\text { Number of } \\
\text { comparisons }\end{array}$ \\
\hline Manufacturer & \multicolumn{4}{|c|}{$\frac{\text { Alternate thickness prediction using Core stacks from }}{50 \mathrm{~mm} \text { (2in.) original product thicknesses }}$} \\
\hline \multirow[b]{2}{*}{ a } & $25(1)$ & 0.7 & 1.1 & 23 \\
\hline & $100(4)$ & -2.6 & 0.6 & 9 \\
\hline \multirow{5}{*}{$\mathrm{b}$} & $25(1)$ & -1.3 & 0.6 & 12 \\
\hline & $100(4)$ & -1.0 & 0.4 & 3 \\
\hline & \multicolumn{4}{|c|}{$\begin{array}{l}\text { Alternate thickness prediction using Math stacks from } 50 \mathrm{~mm} \text { (2in.) original product } \\
\text { thicknesses, including only those that pass Alternate Thickness Criteria } B^{*}\end{array}$} \\
\hline & $25(1)$ & 1.8 & 2.7 & 29 \\
\hline & $100(4)$ & -1.0 & 0.6 & 12 \\
\hline Variety & \multicolumn{4}{|c|}{ Same thickness comparison using Core stack type } \\
\hline \multirow[b]{3}{*}{ Class 1} & $25(1)$ & -0.6 & 3.0 & 12 \\
\hline & $50(2)$ & -2.7 & 0.5 & 18 \\
\hline & $100(4)$ & 2.2 & 3.8 & 6 \\
\hline \multirow[b]{2}{*}{ Class 2} & $25(1)$ & 0.6 & 1.2 & 11 \\
\hline & $50(2)$ & 1.6 & 2.7 & 10 \\
\hline & \multicolumn{4}{|c|}{ Same thickness comparison using Profile Mixed stack type } \\
\hline \multirow[b]{3}{*}{ Class 1} & $25(1)$ & -0.2 & 0.9 & 12 \\
\hline & $50(2)$ & 0.5 & 0.9 & 18 \\
\hline & $100(4)$ & 1.8 & 0.3 & 3 \\
\hline \multirow{5}{*}{ Class 2} & $25(1)$ & 1.5 & 0.7 & 11 \\
\hline & $50(2)$ & 0.8 & 1.0 & 10 \\
\hline & \multicolumn{4}{|c|}{ Same thickness comparison using Math stack type for $25-50 \mathrm{~mm}(1-2$ in.) products } \\
\hline & $25(1)$ & 0.5 & 1.3 & 23 \\
\hline & $50(2)$ & -0.2 & 1.6 & 28 \\
\hline
\end{tabular}

\subsubsection{XPS, Alternate and same thickness predictions}

The Population Marginal Means values for XPS indicate that:

- The most accurate stacks for same thickness predictions are the two mixed stacks and the math stack;

- The most accurate stacks for alternate thickness predictions are the surface and math stacks;

- Using 75-100 mm (3-4 in.) products produces large errors for alternate thickness predictions; and

- The same thickness predictions for $50 \mathrm{~mm}$ (2 in.) products were more accurate than for other product thicknesses.

While the Population Marginal Means values correct for the unbalanced nature of the dataset, the means and standard deviations for the actual test values support these 
conclusions, as shown in Table 7. Looking at these actual test values, it would appear that the best stack selections would be the math stack for alternate thickness predictions and either the profile or math stack for same thickness predictions. For alternate thickness predictions, it appears that only the $50 \mathrm{~mm}$ ( $2 \mathrm{in}$.) products should be used.

Several application factors were also statistically significant in the general linear models. For alternate thickness predictions, product thickness was the most important factor in the model, and the combination of product thickness and manufacturer was the fourth most important, based on the Type III F-values in Table 3. Similarly, variety (standard or high density) was the second most important, and the combination of product thickness and variety were the third most important factor for same thickness predictions. Table 8 shows how the recommended test method options of Math and Profile Mixed stacks perform for these application categories.

Table 7 XPS dataset single-effect results for Error (\%) for test methodology and screening criteria classes

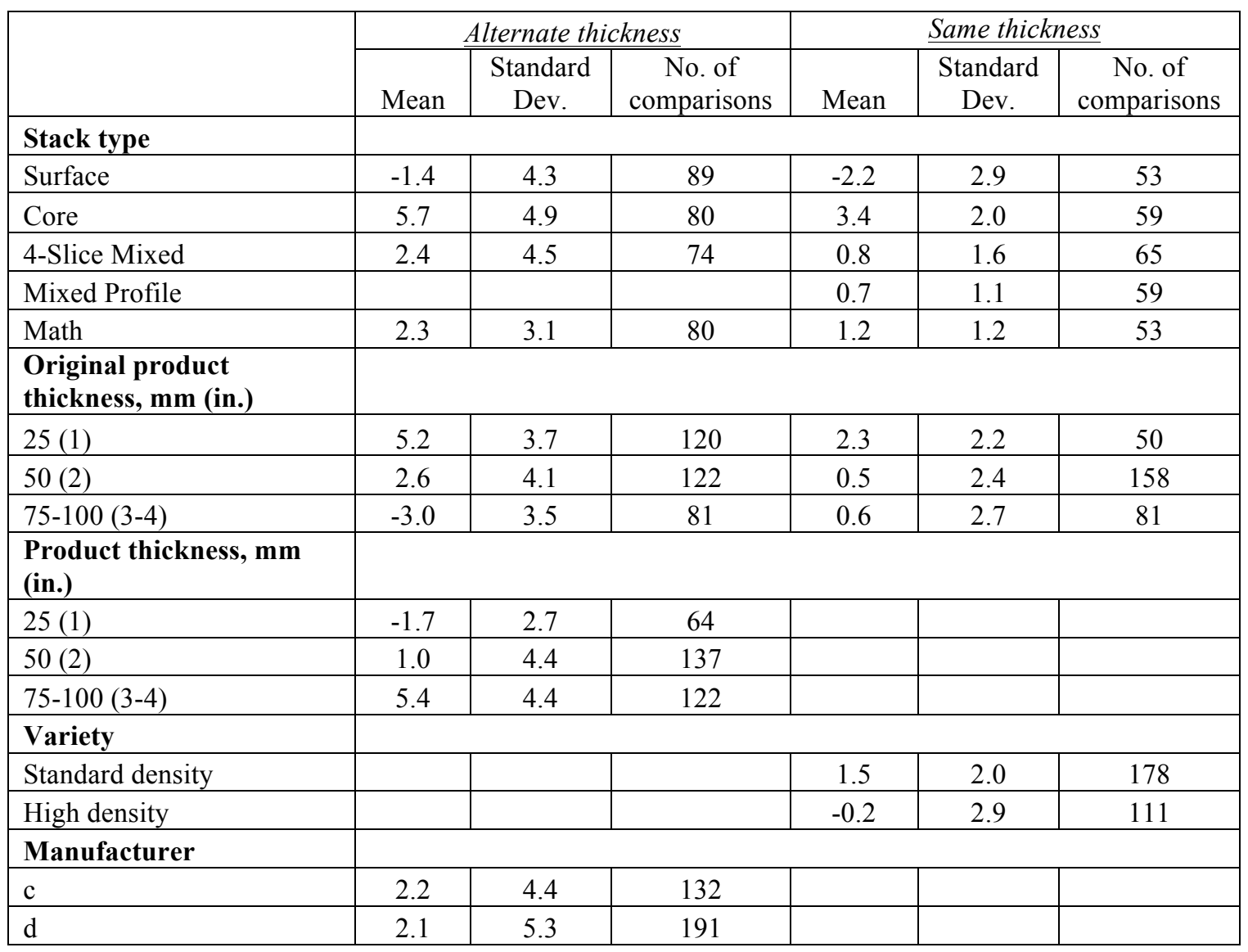


Table 8 Evaluating applications for selected test methodology options for XPS boardstock, Error (\%)

\begin{tabular}{|c|c|c|c|c|}
\hline & $\begin{array}{l}\text { Product thickness, } \\
\text { mm (in.) }\end{array}$ & Mean of Error & $\begin{array}{l}\text { Standard } \\
\text { Deviation of Error }\end{array}$ & $\begin{array}{l}\text { Number of } \\
\text { comparisons }\end{array}$ \\
\hline Manufacturer & \multicolumn{4}{|c|}{$\frac{\text { Alternate thickness prediction using Math stack type from }}{50 \mathrm{~mm} \text { (2in.) original product thicknesses }}$} \\
\hline \multirow[b]{2}{*}{$\mathrm{c}$} & $25(1)$ & 4.2 & 0.0 & 5 \\
\hline & $75-100(3-4)$ & 1.2 & 0.8 & 6 \\
\hline \multirow[b]{2}{*}{ d } & $25(1)$ & 1.8 & 0.5 & 15 \\
\hline & $75-100(3-4)$ & -2.8 & 0.3 & 6 \\
\hline Variety & \multicolumn{4}{|c|}{ Same thickness comparison using Profile Mixed stack type } \\
\hline \multirow[b]{3}{*}{ Class 1} & $25(1)$ & 1.0 & 1.0 & 10 \\
\hline & $50(2)$ & 0.4 & 0.8 & 22 \\
\hline & $75-100(3-4)$ & 3.1 & 0.2 & 6 \\
\hline \multirow[b]{2}{*}{ Class 2} & $50(2)$ & -0.2 & 0.6 & 12 \\
\hline & $75-100(3-4)$ & 0.8 & 0.2 & 9 \\
\hline & \multicolumn{4}{|c|}{ Same thickness comparison using Math stack type } \\
\hline \multirow[b]{3}{*}{ Class 1} & $25(1)$ & 1.8 & 1.3 & 10 \\
\hline & $50(2)$ & 1.1 & 0.7 & 16 \\
\hline & $75-100(3-4)$ & 2.7 & 0.6 & 6 \\
\hline \multirow[b]{2}{*}{ Class 2} & $50(2)$ & 0.5 & 0.9 & 12 \\
\hline & $75-100(3-4)$ & 0.4 & 1.0 & 9 \\
\hline
\end{tabular}

\subsubsection{Data distributions for PIR and XPS boardstock for selected test method options}

In addition to looking at the population marginal means and the dataset means and standard deviations, histograms are useful in examining whether the results are sufficiently clustered near small error values. Core stacks were found useful for PIR products, while Math stacks were found useful for XPS products. For same thickness predictions, Profile Mixed stacks worked well for both products.

Figure 7 to Figure 9 show the relevant data distributions for these test method options. Looking at Figure 7 and Figure 8, remember that the alternate product thickness method is only recommended when the slice origin product thickness is $50 \mathrm{~mm}$ ( 2 in.). Figure 10 shows the data distribution when the Math stack is used to produce predictions for both boardstock products using a slice origin product thickness of $50 \mathrm{~mm}$ ( 2 in.). Another accelerated aging protocol, CAN/ULC S770, also uses the Math stack approach, but is based on an aging factor which is then applied to the initial full thickness value, so the error values reported here will not be applicable to that test method. [Underwriters Laboratory of Canada] 


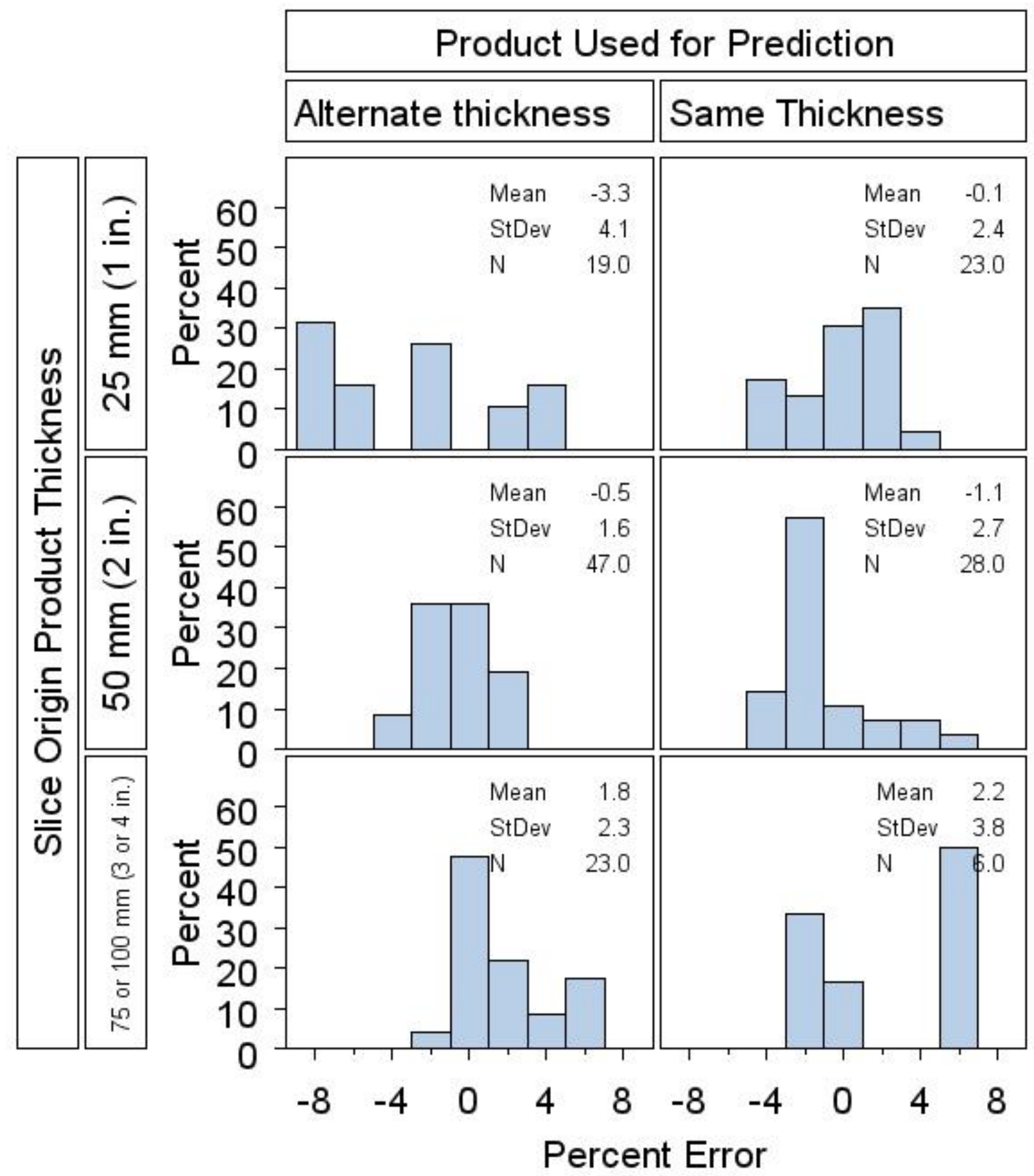

Figure 7 Core stacks used to produce both same and alternate thickness predictions for PIR boardstock 


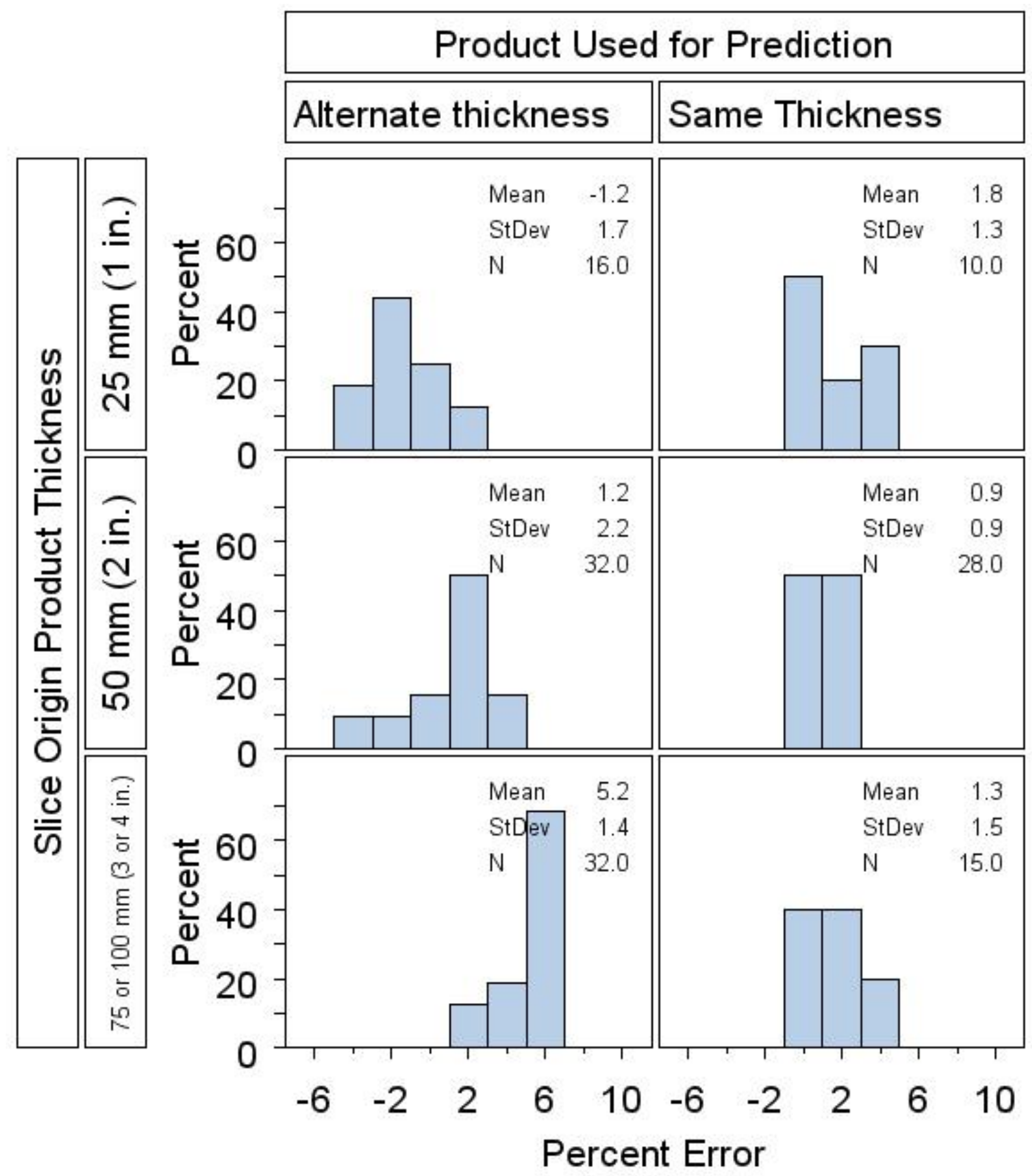

Figure 8 Math stacks used to produce both same and alternate thickness predictions for XPS boardstock 


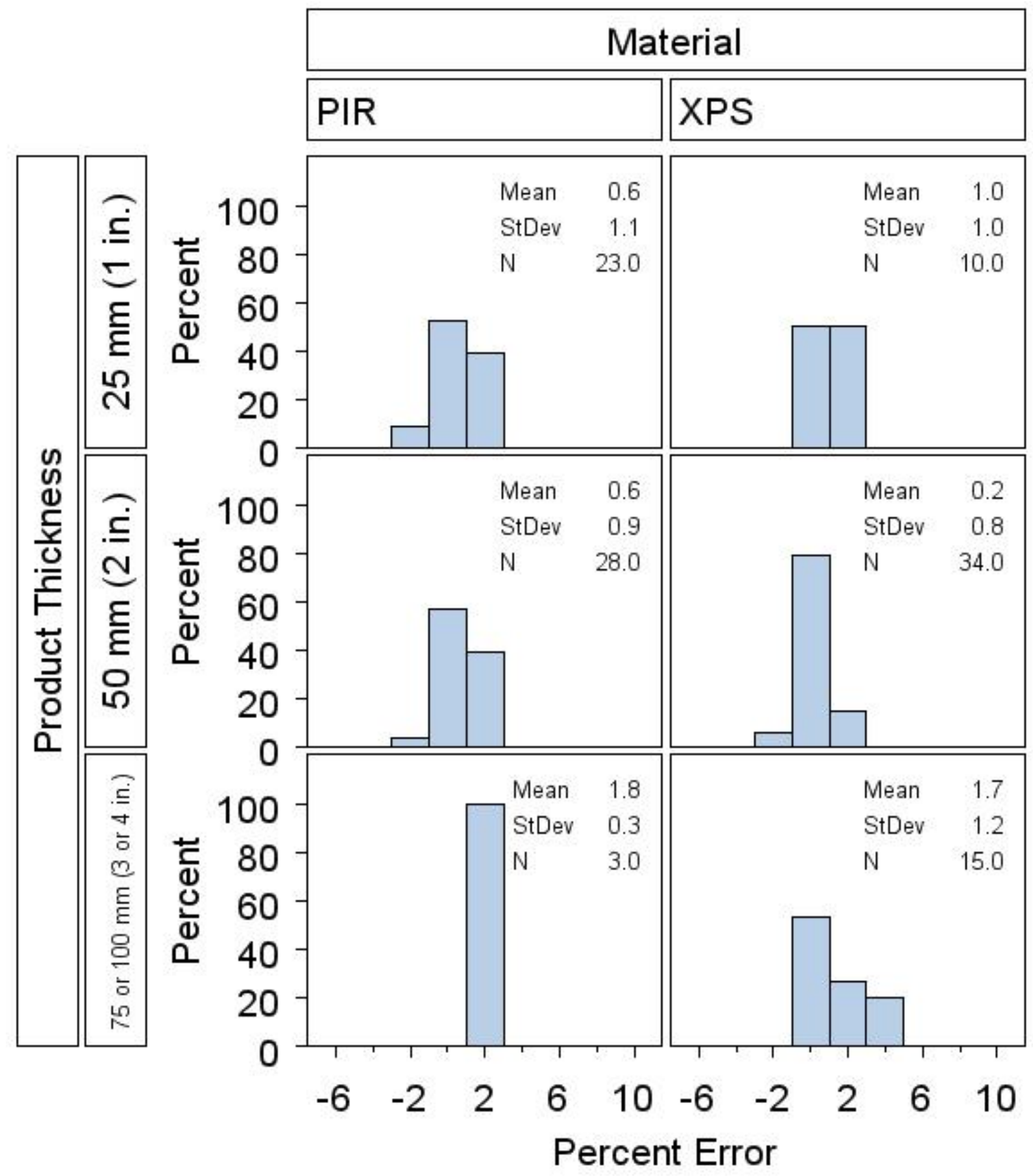

Figure 9 Profile Mixed stacks used to produce Same Thickness predictions for XPS and PIR boardstock 

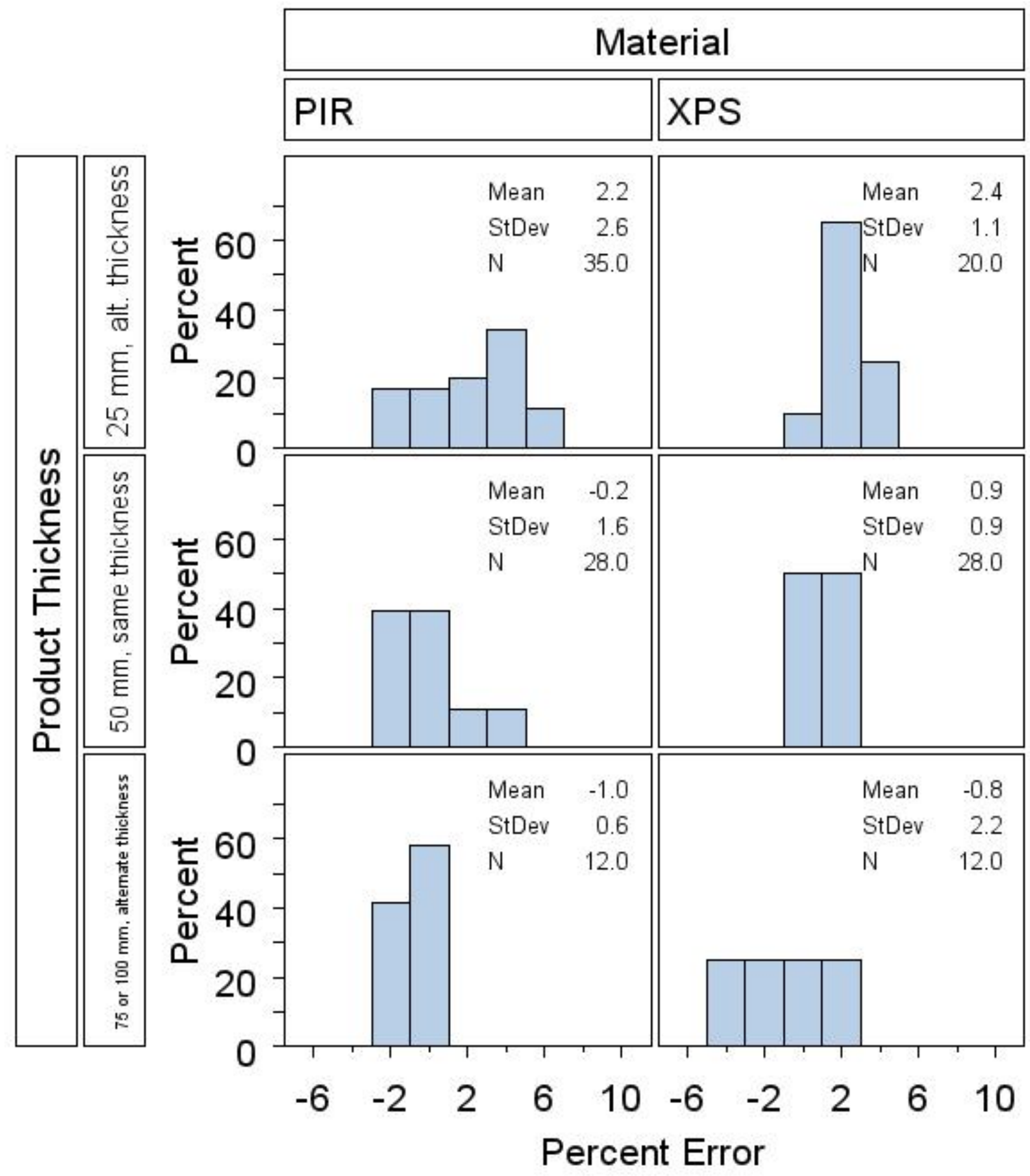

Figure 10 Math stack used to produce both same and alternate thickness predictions for XPS and PIR boardstock, using only $50 \mathrm{~mm}(2 \mathrm{in}$.) products to produce the thin slice stacks. 


\section{RESEARCH TEST METHOD RESULTS}

\subsection{Aging Curve Results}

The research test method, also included in ASTM C1303, is not the focus of the ruggedness test, but it is interesting to compare the results to the prescriptive values in two areas.

First, how well does the single point measurement at a time equivalent to 5 years of aging compare to the integrated average over 15 years? A time period of 15 years is of interest because that is a typical service life for a roof or for many appliances. Standard C1303 provides a research method to calculate the integrated thermal resistance of a product over a selected period of time, as shown in Eq. 5[ASTM (a)]. (In practice, a simple trapezoidal integration of the thin slice data is adequate. [Stovall, et al., 2002]) With this method, it is necessary to measure the thermal conductivity of the thin slices for a period of time equivalent to the full desired service life, and a shorter test period is often preferred. In early research, the aging curve was approximated by a logarithmic relationship over two regions, early aging dominated by air diffusion, and later aging due to blowing agent diffusion, as shown in Eq. 6. [Kumaran and Bomberg, 1990] Based on this approximation, the integrated average thermal resistance over a time period would be equal to the instantaneous thermal resistance after a time period equal to the service life divided by e (2.72). Based on empirical experience, standards CAN/ULC S770 and ASTM C1303 both call for a measurement of the instantaneous value equivalent to 5 years to represent the average performance over 15 years. As shown in Table 9, the five-year instantaneous thermal conductivity matches the integrated 15 -year value very closely, usually within $\sim 1 \%$.

$$
\begin{gathered}
R_{\text {design }}=\frac{\int_{0}^{\text {Service Life }} R(\tau) d \tau}{\text { Service life }} \quad \text { Eq. } 5 \\
R(\tau)=\left(R_{\text {init }}-A \times \ln \left(\tau_{A}\right)\right)-B \times \ln \left(\tau-\tau_{A}\right) ; \text { for } \tau>\tau_{A}
\end{gathered}
$$

where:

$\mathrm{A}=$ empirical constant from first stage of aging, $\mathrm{K} / \mathrm{W}$

$\mathrm{B}=$ empirical constant from second stage of aging, $\mathrm{K} / \mathrm{W}$

$\tau_{\mathrm{A}}=\quad$ time period, days

$\tau_{\mathrm{A}}=\quad$ time period for first stage of aging, days

\begin{tabular}{|c|c|c|c|c|}
\hline \multirow[t]{2}{*}{ Material } & \multirow[t]{2}{*}{ Material Variation } & \multicolumn{3}{|c|}{$\begin{array}{c}\text { Difference compared to } 15 \text {-year integrated } \\
\text { average }, \%\end{array}$} \\
\hline & & Mean & Minimum & Maximum \\
\hline \multirow[t]{2}{*}{ PIR } & Class 1 & -0.1 & -1.1 & 0.9 \\
\hline & Class 2 & -1.0 & -2.7 & 0.3 \\
\hline \multirow[t]{2}{*}{ XPS } & High density (greater compressive strength) & 1.1 & 0.5 & 1.6 \\
\hline & Standard density & 0.4 & -0.9 & 1.5 \\
\hline
\end{tabular}

Table 9 Research Method's 5-Year Prediction of Core Slice Stack [Stovall, 2009] 
Second, does the shape and variance of the points on the aging curve give any indication of the possible influence of the reliance on a single measurement vs. a series of measurements? For this comparison, only the results from core stacks were analyzed using the research methodology and compared to the results from the prescriptive method. Figure 11 and Figure 12 show two curves based upon actual data from this ruggedness test. The second case was selected because it represents the worst case from this ruggedness test with regard to a questionable data point. Our best guess is that the specimen placed in the heat flux meter apparatus did not match the label on the schedule or the label recorded independently with the results. This is not a common occurrence, but it can happen. With the prescriptive method, it is therefore important to use an adequate number of replicate specimens. With the research method, the problem is self-evident, and the data point can be discarded without significantly impacting the accuracy of the result.

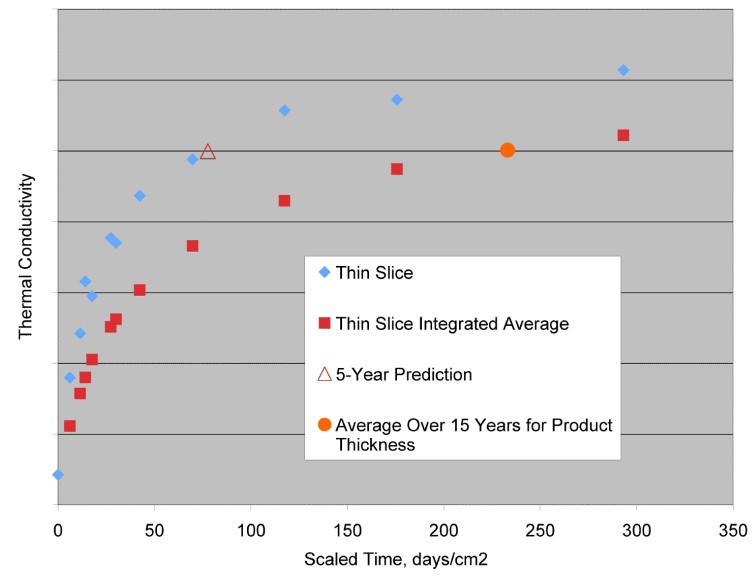

Figure 11 Typical comparison of thin slice aging curve, 5-year point prediction, and integrated average values [Stovall, 2009]

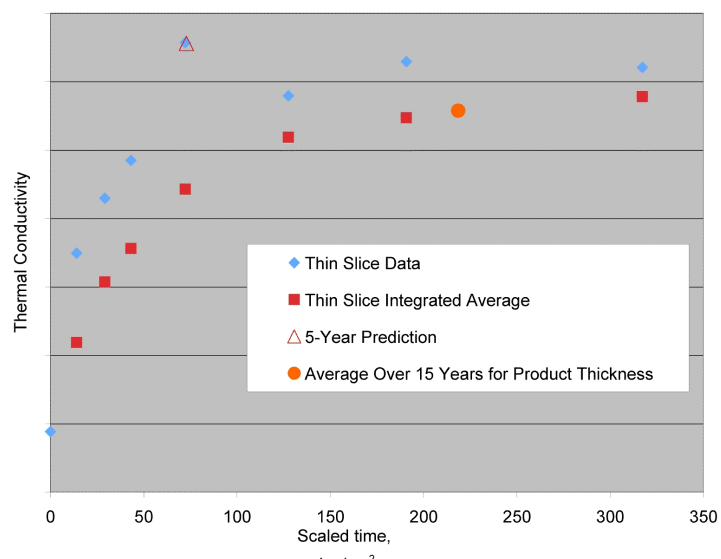

Figure 12 Worst case comparison of thin slice aging curve, 5 -year point prediction, and integrated average values [Stovall, 2009]

\subsection{Magnitude of Errors Due to the Destruction of Surface Layer Cells, or TDSL}

It has been previously shown that the destroyed surface layer(s) of the thin slices introduces two types of errors in the accelerated aging predictions of thermal conductivity. [Stovall, 2007] First, the difference between the geometric thickness and the diffusion thickness causes a difference in the amount of time calculated to align the thin slice aging to the full thickness aging. Second, every measurement of the thermal conductivity of the stack of thin slices includes the influence of the destroyed surface cells that are filled with atmospheric gases.

The error due to the difference between the time calculations is shown in Eq. 7. The parameter s, shown in Eq. 8, represents the portion of the thickness that is the total TDSL, because it includes both cut surfaces. The error in the scaled time, shown in Eq. 7, is then approximately equal to twice the total TDSL. The translation of the time error into the error in the predicted thermal conductivity depends both upon the magnitude of the time error and the rate at which the foam is aging when it reaches that time. [Stovall, 2007] 


$$
\begin{aligned}
& \text { Error }_{\text {time }}=\frac{\left(\text { Scaled time }_{\text {used }}-\text { Scaled time }_{\text {correct }}\right)}{\text { Scaled time }_{\text {correct }}}=\frac{\left(2 s-s^{2}\right)}{\left(1-2 s+s^{2}\right)} \\
& \mathrm{s}=\frac{\left(x_{1}+x_{3}\right)}{\left(x_{1}+x_{2}+x_{3}\right)}
\end{aligned}
$$

Where:

$\mathrm{x}_{1}=$ thickness of destroyed surface layer on one side of the slice

$\mathrm{x}_{2}=$ thickness of body of the slice with no cut cells

$\mathrm{x}_{3}=$ thickness of destroyed surface layer on the other side of the slice

The second error is introduced by the difference between the thermal resistivity in the broken cells, which are already fully aged, and the thermal resistivity in the closed-cell portion of the slice, which is undergoing the aging behavior of interest. Using a series resistance representation, that error is shown in Eq. 9.[Stovall, 2007] This error is smaller in magnitude than the time error. For example, for an s of $10 \%$ and a $\mathrm{C}$ of 1.2 , the magnitude of Error $_{\mathrm{R}}$ is less than $2 \%$.

$$
\text { Error }_{\mathrm{R}}=\frac{\left[R_{\text {measured }}(t)-R_{c c}(t)\right]}{R_{c c}(t)}=s \frac{(1-C)}{C}, \quad \text { where } C=\frac{R_{c c}(t)}{R_{\text {final }}}
$$

where:

$$
\begin{array}{lll}
\mathrm{R}_{\text {measured }}(\mathrm{t})= & \text { Thermal resistivity measured at time } \mathrm{t}, \mathrm{K} / \mathrm{W} \\
\mathrm{R}_{\text {final }}= & \text { Final (time } \rightarrow \infty \text { ) thermal resistivity of fully aged foam, } \mathrm{K} / \mathrm{W} \text {, and } \\
\mathrm{R}_{\mathrm{cc}}(\mathrm{t}) & = & \text { Thermal resistivity of undamaged closed cell foam at time } \mathrm{t}, \mathrm{K} / \mathrm{W} .
\end{array}
$$

Because the TDSL was measured for the ruggedness specimens, and because additional data were taken during this ruggedness test to provide a full aging curve for every thin-slice stack, it is possible to quantify the error introduced by each of these two factors. The total error is then represented as the square root of the sum of the errors squared. Figure 13 shows that the error is greater for core slices, because they have two cut surfaces and therefore a greater amount of total TDSL. The combined error is expected to be greater for thicker products because the aging rate is much greater during the earliest stage of aging, which corresponds to the shorter test times for thicker products. Small variations in test time during this early aging stage will therefore result in greater differences in the measured thermal conductivity. However, Figure 14 shows the impact of a shorter testing time for thicker products has a relatively small influence for the specimens tested here. 


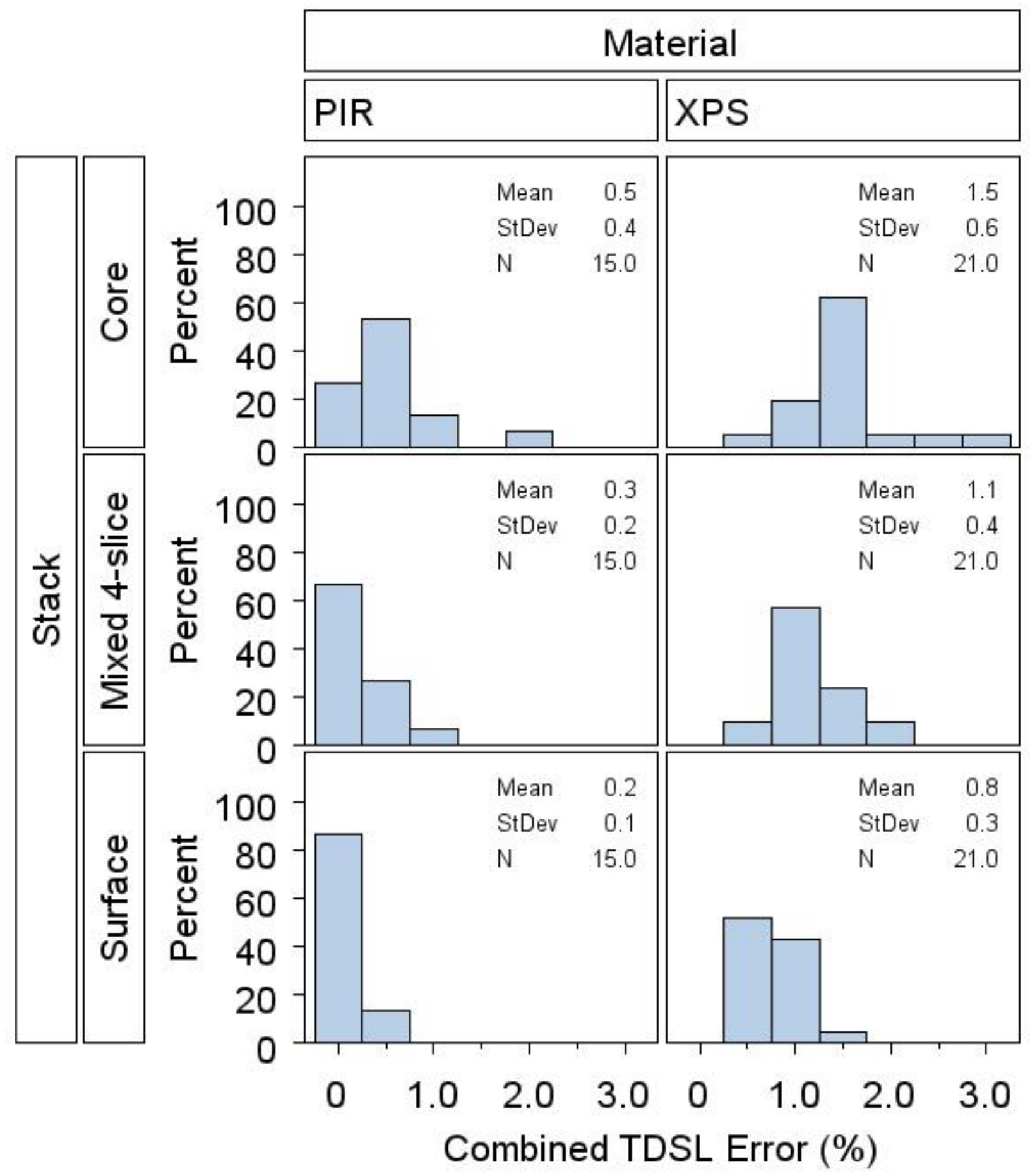

Figure 13 Total error in predicted thermal conductivity due to TDSL, variations among stack types Surface, Core, and Four-slice Mixed 


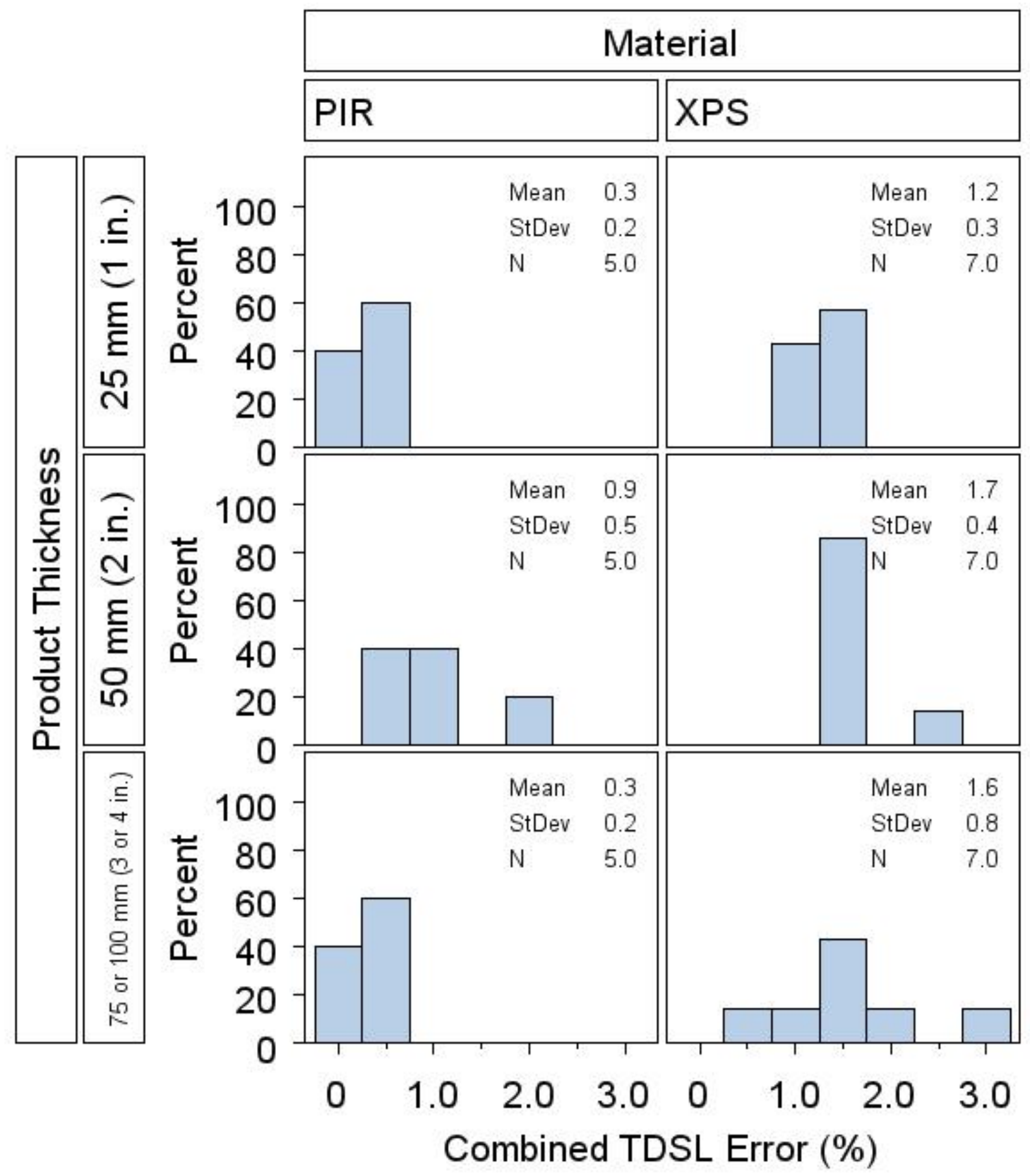

Figure 14 Total error in predicted thermal conductivity due to TDSL, variations according to product thicknesses from 25 to $100 \mathrm{~mm}$ ( 1 to $4 \mathrm{in}$.) for core stacks only. 


\section{DISCUSSION AND RECOMMENDATIONS}

The current homogeneity test appears to be of limited value. It showed no statistical significance for XPS, and even for PIR, the values were contrary to the expected result. That is, the predictions for 'more homogenous' materials, as defined by the 2010 version of C1303, provided less accurate predictions for 5-year thermal conductivity. However, this may well reflect the relatively good degree of homogeneity in these factory-manufactured foam insulation products. Every specimen tested had a homogeneity value between 92 and $100 \%$ using the $2010 \mathrm{C} 1303$ definition.

Although this qualification requirement seems unneeded for the products included in the ruggedness test, it is still desirable to maintain some form of homogeneity qualification in the standard because the theoretical foundation for the test method is based upon the assumption of product homogeneity. For that purpose, a simpler measurement of homogeneity is proposed in Appendix C. That proposed qualification test will be simpler to execute, but will require broader acceptance criteria because it spreads out the calculated values for 'homogeneity' from 85 to $110 \%$, so that reasonable criteria could be from 85 to $115 \%$.

For alternate product thickness applications, that is, where thin slices produced using one product thickness are used to predict the five-year thermal conductivity for products of another thickness, the $2010 \mathrm{C} 1303$ requires two separate qualification tests. Both of these tests use the measured thermal conductivity of stacks of core and surface slices. The first compares the aging rates of the two products during the period from 1 to $30 \mathrm{days} / \mathrm{cm}^{2}$. The second compares the thermal conductivities of the two products after 30 days $/ \mathrm{cm}^{2}$. The aging rate results showed no significance whatsoever in any of the analyses. The thermal conductivity comparisons at 30 days $/ \mathrm{cm}^{2}$, however, showed some utility in screening out some of the greatest errors. Although limiting the stack type and slice origin had the same effect for the PIR and XPS boardstock products, this test should be maintained for other products not included in this ruggedness test.

The test method recommendations for the two products included in this ruggedness test, based on both the population marginal mean analysis (see Table 3) and the raw data analysis (see the error distributions in Figure 7 to Figure 10), are summarized in Table 10. The results from the raw data analysis for these recommendations are further summarized in Table 11 and Table 12. Some recommendations are common to both materials: (1) Profile stack is excellent for same thickness predictions, (2) the Math stack is acceptable for alternate thickness predictions, and (3) don't use slices from 75-100 mm (3-4 in.) products for alternate thickness predictions - slices taken from a $50 \mathrm{~mm}(2 \mathrm{in}$.) product gave the best results. Remember that:

- A positive error indicates the predicted thermal conductivity was too high - and therefore the predicted thermal resistance was too low.

- A negative error indicates the predicted thermal conductivity was too low - and therefore the predicted thermal resistance was too high. 
Table 10 Summary of recommendations for both product types included in the ruggedness test.

\begin{tabular}{|c|c|c|}
\hline & PIR & XPS \\
\hline $\begin{array}{l}\text { Same } \\
\text { thickness }\end{array}$ & $\begin{array}{l}\text { Math or Profile mixed stack except } \\
\text { for } 100 \mathrm{~mm}(4 \mathrm{in} .) \text { products } \\
\text { Core stack except for } 100 \mathrm{~mm} \text { (4 in.) } \\
\text { products only }\end{array}$ & $\begin{array}{ll}\text { - } & \text { Profile mixed stack } \\
\text { - } & \text { Math stack }\end{array}$ \\
\hline $\begin{array}{l}\text { Alternate } \\
\text { thickness }\end{array}$ & $\begin{array}{l}\text { - Math stacks from } 50 \mathrm{~mm}(2 \mathrm{in} .) \\
\text { products that pass the alternate } \\
\text { thickness criteria } \\
\text { - Core stacks from } 50 \mathrm{~mm}(2 \mathrm{in} .) \\
\text { products. }\end{array}$ & $\begin{array}{ll}\text { - } & \text { Math stack from } 50 \mathrm{~mm}(2 \mathrm{in} .) \\
\text { products. } \\
\text { - }\end{array}$ \\
\hline
\end{tabular}

Table 11 PIR dataset results for Error (\%) corresponding to recommendations

\begin{tabular}{|c|c|c|c|c|c|}
\hline $\begin{array}{l}\text { Slice origin } \\
\text { product thickness, } \\
\text { mm (in.) }\end{array}$ & $\begin{array}{c}\text { Alternate } \\
\text { thickness } \\
\text { criteria B* }\end{array}$ & Stack type & Mean & $\begin{array}{l}\text { Standard } \\
\text { Deviation }\end{array}$ & $\begin{array}{c}\text { Number of } \\
\text { comparisons }\end{array}$ \\
\hline \multicolumn{6}{|c|}{ Same thickness } \\
\hline \multirow[t]{3}{*}{$25(1)$} & & Core & -0.1 & 2.4 & 23 \\
\hline & & Profile Mixed & 0.6 & 1.1 & 23 \\
\hline & & Math & 0.5 & 1.3 & 23 \\
\hline \multirow[t]{3}{*}{$50(2)$} & & Core & -1.1 & 2.7 & 28 \\
\hline & & Profile Mixed & 0.6 & 0.9 & 28 \\
\hline & & Math & -0.2 & 1.6 & 28 \\
\hline \multicolumn{6}{|c|}{ Alternate thickness } \\
\hline \multirow[t]{4}{*}{$50(2)$} & Pass & Core & -0.6 & 1.6 & 41 \\
\hline & Fail & & -0.3 & 0.9 & 6 \\
\hline & Pass & Math & 1.0 & 2.6 & 41 \\
\hline & Fail & & 4.0 & 0.9 & 6 \\
\hline
\end{tabular}

Table 12 XPS dataset results for Error (\%) corresponding to recommendations

\begin{tabular}{|c|c|c|c|c|}
\hline $\begin{array}{l}\text { Product thickness, } \\
\text { mm (in.) }\end{array}$ & Stack type & Mean & $\begin{array}{l}\text { Standard } \\
\text { Deviation }\end{array}$ & $\begin{array}{c}\text { Number of } \\
\text { comparisons }\end{array}$ \\
\hline \multicolumn{5}{|c|}{ Same thickness } \\
\hline \multirow[t]{2}{*}{$25(1)$} & Profile Mixed & 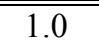 & 1.0 & 10 \\
\hline & Math & 1.8 & 1.3 & 10 \\
\hline \multirow[t]{2}{*}{$50(2)$} & Profile Mixed & 0.2 & 0.8 & 34 \\
\hline & Math & 0.9 & 0.9 & 28 \\
\hline \multirow[t]{2}{*}{$75-100(3-4)$} & Profile Mixed & 1.7 & 1.2 & 15 \\
\hline & Math & 1.3 & 1.5 & 15 \\
\hline \multicolumn{5}{|c|}{ Alternate thickness, from original product thickness of $50 \mathrm{~mm}(2 \mathrm{in})}$. \\
\hline \multirow[t]{2}{*}{$25(1)$} & Math & 2.4 & 1.1 & 20 \\
\hline & Surface & 1.1 & 1.4 & 20 \\
\hline \multirow[t]{2}{*}{$75-100(3-4)$} & Math & -0.8 & 2.2 & 12 \\
\hline & Surface* & -6.3 & 3.1 & 21 \\
\hline
\end{tabular}




\subsection{Changes already made to the standard}

The ruggedness test experience has already produced some useful information that is reflected in modifications to the test procedure between 2008 and 2012.

Past experience had shown that interpolation between data points over some reasonable time period produces values that match within a very small margin. Such flexibility in the prescriptive test procedure was desired to help accommodate test schedules that call for measurement on popular holidays or vacation periods. Therefore, ruggedness test data was explored to quantify the impact of such interpolation upon the predicted thermal conductivity values. Based upon this evaluation, the standard was modified to allow such interpolation within prescribed limits.

Following a few early errors in calculating the test times for the homogeneity and alternate product thickness qualification tests, equations were added to the ASTM C 1303 test procedure to clarify the calculation of test times. Second, the acceptable time limit on the $24 \mathrm{~h}$ test was broadened from 0.5 to $1 \mathrm{~h}$ to facilitate the execution of the two (core and surface slice stacks) tests with a single heat flux meter apparatus. Third, an example has been prepared for the qualification section of the test procedure to outline all the necessary calculations.

\subsection{Changes to be considered}

The current version of $\mathrm{C} 1303$ allows the use of the three test stack configurations as replicates. The issue of sufficient replicate measurements is obviously important, as demonstrated here by the emergence of at least one obvious outlier. Without the multiple measurements that produce the typical aging curve in the research method, an erroneous data point will be less obvious.

Recommendations are included in Appendix $\mathrm{C}$ for possible revisions to the homogeneity and alternate thickness criteria. These suggested approaches would no longer require a test measurement at $24 \mathrm{~h} / \mathrm{cm}^{2}$, instead basing the criteria solely on comparisons of thermal conductivity taken 30 days $/ \mathrm{cm}^{2}$ after the slicing is complete. This would simplify the test procedure and, based on the experience gained during this ruggedness test, accomplish the same goals. 


\section{APPENDIX A. RUGGEDNESS TEST PROTOCOL}

[Excerpted from Stovall and Bogdan, 2007]

A ruggedness test is designed to "test the test", not to test the materials. However, one of the questions addressed in this study is the efficacy of the test method when applied to a variety of foam insulation materials. Some of the variables in this study are therefore inherent to the material and others are determined by the test procedure, as outlined in Table 13. The product variables shown here were selected as representative of commercially available products in 2007, when the test began. Other test methods were also employed during the execution of the ASTM C1303 test procedure, including:

- Density measured according to ASTM D1622 [ASTM International (b)]

- Thermal conductivity measured according to ASTM C518 [ASTM International (c)]

- $\quad$ Thickness of the destroyed surface layer measured according to ASTM D6226 [ASTM International (d)]

Table 13 Variables Considered in the Ruggedness Test

\begin{tabular}{|c|c|c|c|c|}
\hline \multicolumn{5}{|c|}{ Product Variables } \\
\hline Material Type & Manufacturers & \multicolumn{2}{|l|}{ Material Variations } & $\begin{array}{l}\text { Nominal Product Thickness } \\
\text { Used as Specimen Source } \\
(\mathrm{mm})\end{array}$ \\
\hline \multirow[t]{2}{*}{ Polyisocyanurate } & \multirow{2}{*}{2} & \multicolumn{2}{|c|}{ Type II, Class 1, Grade 1 (black facer) } & $25,50,100$ \\
\hline & & \multicolumn{2}{|c|}{ Type II, Class 2 (white facer) } & 25,50 \\
\hline \multirow{2}{*}{$\begin{array}{l}\text { Extruded } \\
\text { Polystyrene }\end{array}$} & \multirow{2}{*}{2} & \multirow{2}{*}{\multicolumn{2}{|c|}{$\begin{array}{l}\text { Density: } 27 \mathrm{~kg} / \mathrm{m}^{3}\left(1.7 \mathrm{lb} / \mathrm{ft}^{3}\right)( \pm 10 \%) \\
\text { Density: } 48 \mathrm{~kg} / \mathrm{m}^{3}\left(3.0 \mathrm{lb} / \mathrm{ft}^{3}\right)( \pm 10 \%)\end{array}$}} & $25,50,100$ \\
\hline & & & & 50,100 \\
\hline \multicolumn{5}{|c|}{$\underline{\text { Test Variables }}$} \\
\hline Slice Thickness & \multicolumn{2}{|c|}{ Product Variables } & \multicolumn{2}{|c|}{ Stack Composition } \\
\hline \multirow[t]{3}{*}{$10 \mathrm{~mm}$} & \multirow{3}{*}{\multicolumn{2}{|c|}{ All of the above }} & \multicolumn{2}{|c|}{ Core slices only } \\
\hline & & & \multicolumn{2}{|c|}{ Surface slices only } \\
\hline & & & \multicolumn{2}{|c|}{2 Surface and 2 Core slices } \\
\hline $10 \mathrm{~mm}$ & $100 \mathrm{~mm}$ thick pr & ucts only & Full cros & ection \\
\hline \multirow[t]{6}{*}{8 and $12 \mathrm{~mm}$} & \multirow{3}{*}{\multicolumn{2}{|c|}{ One $50 \mathrm{~mm}$ thick polyisocyanurate product }} & \multicolumn{2}{|c|}{ Core slices only } \\
\hline & & & \multicolumn{2}{|c|}{ Surface slices only } \\
\hline & & & \multicolumn{2}{|c|}{2 Surface and 2 Core slices } \\
\hline & \multirow{3}{*}{\multicolumn{2}{|c|}{$\begin{array}{l}\text { One } 50 \mathrm{~mm} \text { thick extruded polystyrene } \\
\text { product }\end{array}$}} & \multicolumn{2}{|c|}{ Core slices only } \\
\hline & & & \multicolumn{2}{|c|}{ Surface slices only } \\
\hline & & & \multicolumn{2}{|c|}{2 Surface and 2 Core slices } \\
\hline
\end{tabular}

Table 13 outlines a large number of variables encompassed within the ruggedness test. To the extent possible in any experiment, all other factors were held constant. The factors specifically addressed include:

- A single test laboratory performed all specimen preparation and thermal conductivity 
measurements.

- A single band saw was used for all thin slice preparation.

- A single ASTM C 518 measurement was prepared for each of the thin-slice combinations outlined in Table 13. (An initial investigation of the ASTM C 518 convergence criteria for these apparatus was made and the results were applied consistently for all thin slice measurements.)

- Multiple ASTM C 518 measurements were made for full thickness specimens whenever possible.

- All ASTM C 518 measurements made on one of four heat flux meter apparatus, regularly control-charted using the same stable specimen. This test environmental factor was included in the statistical analysis.

- To the extent possible, all sample thicknesses for the same density (for XPS) and the same facers (for polyisocyanurate) were provided from the same plant location.

- Samples were provided in $1.2 \times 1.2 \mathrm{~m}(4 \times 4 \mathrm{ft}$.) pieces, except for some products that are only available in $0.6 \times 1.7 \mathrm{~m}(2 \times 8 \mathrm{ft}$.) boards.

- All thin-slice specimens were extracted in the same manner from the full thickness product sheets.

- All shuffling of thin slices between the core, surface, and mixed stacks took place in the same order for each product.

The following test factors were defined by ASTM C 1303:

- All samples were shipped between 7 and 12 days after the date of manufacture and all thin slice specimens were prepared between 14 and 21 days after the date of manufacture.

- All ASTM C 518 measurements were made at a mean temperature of $24^{\circ} \mathrm{C}\left(75^{\circ} \mathrm{F}\right)$ with a temperature difference of $22^{\circ} \mathrm{C}\left(40^{\circ} \mathrm{F}\right)$.

- All thin slices were prepared to meet the specifications outlined in C1303, including flatness and agreement in average thickness for every slice within the stack.

The test schedule was designed to compare the predicted aged values, based upon thinslice stack measurements, at time periods of $1,2,3$, and 5 years for every product. The test schedule also includes measurements to test the ability of thin slices prepared from one product thickness to predict the 5-year thermal resistance of the "Alternate Product Thickness". Time periods elapsed between specimen preparation and thermal conductivity measurements were calculated as shown in Eq. 10 (from ASTM C 1303) using the values summarized in Table 14. For the purpose of this calculation, the average slice thickness for surface slices does not include the thickness of any facing material.

$$
\text { Test Time }=\left[\frac{\text { Average Slice Thickness }}{\text { Full Product Thickness }}\right]^{2} \times \text { Time }_{\text {Full Thickness }}
$$


Table 14 Test Schedule of ASTM C518 Thermal Conductivity Measurements

\begin{tabular}{|c|c|c|c|}
\hline $\begin{array}{l}\text { Nominal product } \\
\text { thickness used as } \\
\text { specimen source } \\
(\mathrm{mm})\end{array}$ & Specimen & $\begin{array}{l}\text { "Full Product } \\
\text { Thickness" used to } \\
\text { calculate "Test Time" } \\
\text { in Eq. 9* } \\
(\mathrm{mm})\end{array}$ & $\begin{array}{l}\text { "Time } \text { full thickness" used to } \\
\text { calculate "Test Time" in } \\
\text { Eq. } 9 \\
\text { (years) }\end{array}$ \\
\hline \multirow[t]{4}{*}{25} & \multirow[t]{3}{*}{ Thin stacks } & 25 & $1,2,3,5$ \\
\hline & & $50(\mathrm{AP}) * *$ & 5 \\
\hline & & $100(\mathrm{AP})$ & 5 \\
\hline & Full thickness & Actual time & $0.5,1,2,3,5$ \\
\hline \multirow[t]{4}{*}{50} & \multirow[t]{3}{*}{ Thin stacks $^{* *}$} & $25(\mathrm{AP})$ & $2,3,5$ \\
\hline & & 50 & $1,2,3,5$ \\
\hline & & $100(\mathrm{AP})$ & $2,3,5$ \\
\hline & Full thickness & Actual time & $0.5,1,2,3,5$ \\
\hline \multirow[t]{4}{*}{100} & \multirow[t]{3}{*}{ Thin stacks } & $25(\mathrm{AP})$ & 5 \\
\hline & & 50 (AP) & 5 \\
\hline & & 100 & $1,2,3,5$ \\
\hline & Full thickness & Actual time & $0.5,1,2,3,5$ \\
\hline 25,50, and 100 & \multicolumn{3}{|c|}{ 24-hour and 30-day tests as described in ASTM C 1303 Annex A1 } \\
\hline \multicolumn{4}{|c|}{$\begin{array}{l}{ }^{*} \text { The measured thickness of the full thickness product, as opposed to the nominal thickness, was used when } \\
\text { available. } \\
\text { thickness specimen was included for comparison in Table } 4 \text {. For example, Table } 4 \text { shows that only } 25 \text { and } \\
50 \mathrm{~mm} \text { product thicknesses are tested for Type II, Class } 2 \text { polyisocyanurate, so there is no need to prepare a } \\
\text { prediction for a } 100 \mathrm{~mm} \text { product thickness for that category. }\end{array}$} \\
\hline
\end{tabular}




\section{APPENDIX B. TEST SPECIMEN CHARACTERIZATION}

\section{B.1 Test specimen preparation [from Stovall and Bogdan, 2007]}

The manufacturers provided sets of full-size product boards on a schedule consistent with the $\mathrm{C} 1303$ prescriptive test method. That is, they were shipped from the factory to the laboratory 7 to 20 days after production and the thin slices were prepared 14 to 21 days after production. These product boards came in two sizes, $1.2 \times 1.2 \mathrm{~m}(4 \mathrm{x} 4 \mathrm{ft}$.) and $0.6 \times 2.4 \mathrm{~m}(2$ x $8 \mathrm{ft}$.).

Full thickness boards [nominal size $1.4 \mathrm{~m}^{2}\left(16 \mathrm{ft}^{2}\right)$ ] were set aside to age undisturbed within a conditioned laboratory $\left(\sim 22^{\circ} \mathrm{C}\left(72^{\circ} \mathrm{F}\right)\right.$ and $\left.40-60 \% \mathrm{RH}\right)$ so that their thermal conductivity could be compared to the thin-slice aging predictions. At intervals shown in the test schedule in Table 5, full thickness test specimens were extracted from a full-size board.

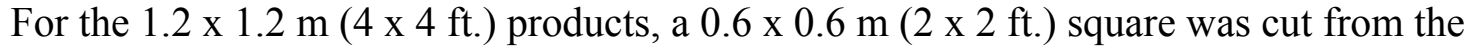
center. See Figure 15. The thermal conductivity of this board was then measured at least once on a $0.6 \times 0.6 \mathrm{~m}(2 \times 2 \mathrm{ft}$.) heat flux meter apparatus (HFMA). For 25 and 50-mm thick products, this specimen was then cut into four $0.3 \times 0.3 \mathrm{~m}(1 \times 1 \mathrm{ft}$.) squares which were used in a $0.3 \times 0.3 \mathrm{~m}(1 \times 1 \mathrm{ft}$.) HFMA. For the $0.6 \times 2.4 \mathrm{~m}(2 \times 8 \mathrm{ft}$. $)$ products, multiple $0.6 \times 0.6$ $\mathrm{m}(2 \times 2 \mathrm{ft}$.) squares were cut, at least $0.15 \mathrm{~m}$ (6 inches) away from either end of the board, and the thermal conductivity of each was then measured using the $0.6 \times 0.6 \mathrm{~m}(2 \times 2 \mathrm{ft}$.) HFMA. For 25 and $50-\mathrm{mm}$ thick products, a $0.3 \times 0.3 \mathrm{~m}(1 \mathrm{x} 1 \mathrm{ft}$. $)$ specimen was then cut from the center of each $0.6 \times 0.6 \mathrm{~m}(2 \times 2 \mathrm{ft}$.) square, which was then placed in a $0.3 \times 0.3 \mathrm{~m}$ (1 x $1 \mathrm{ft}$.) HFMA.

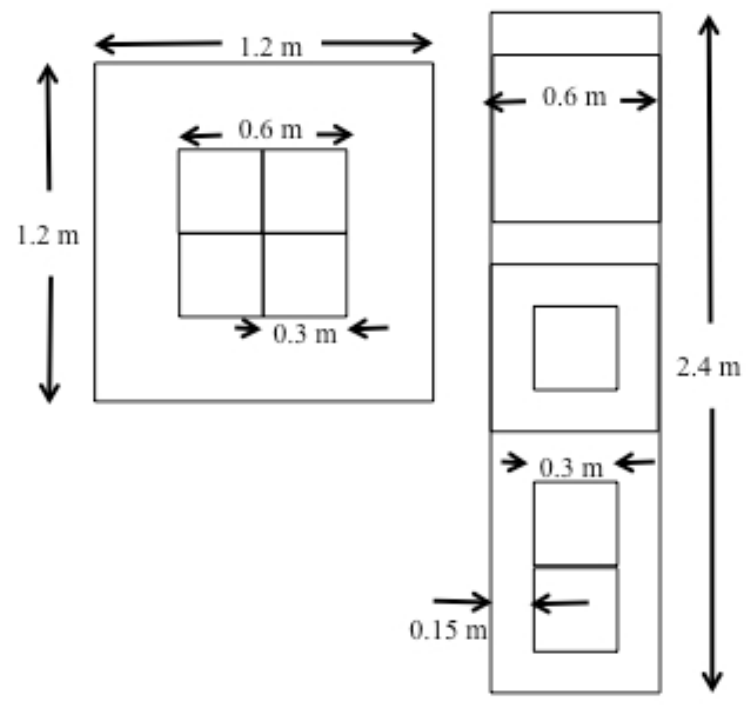

Figure 15 Specimen extraction from the full size product boards

In order to produce the thin slices, $0.3 \mathrm{~m}$ (12 in.) squares were first extracted from the

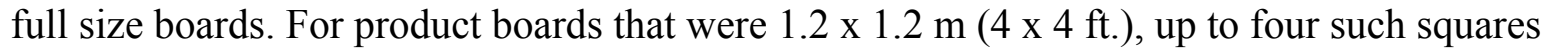
were harvested from the center of each for thin slicing, as shown in Figure 15. For product boards that were $0.6 \times 2.4 \mathrm{~m}(2 \times 8 \mathrm{ft}$.), up to seven such squares were extracted along the length of the board, maintaining the minimum distance of $0.15 \mathrm{~m}(6 \mathrm{in}$.) away from the edge, as required by the $\mathrm{C} 1303$ prescriptive method. 
Thin slices were then cut from these smaller squares using a band saw with 1 tooth $/ \mathrm{mm}$ (14 teeth/in.) according to the $\mathrm{C} 1303$ specimen extraction requirements, producing 247 thin slices. Eight thickness measurements were made on each slice as required by $\mathrm{C} 1303$ and all slice flatness and slice uniformity criteria of the prescriptive method were satisfied. This often required the production of extra slices, especially for the 8-mm (0.03-in.)-thick specimens. More than 1900 slice thickness measurements were made in total. Table 15 summarizes the slice flatness and stack uniformity measurements. The slice flatness is quantified based upon the magnitude of the maximum deviation from the average for each slice. The stack uniformity is quantified based upon the magnitude of the maximum deviation from the average for each stack. The slices were stored in the laboratory near the heat flux meter apparatus. The environmental conditions in that area are usually at $23^{\circ} \mathrm{C}\left(73^{\circ} \mathrm{F}\right)$ and $35 \% \mathrm{RH}$. 
Table 15 Slice flatness and stack uniformity

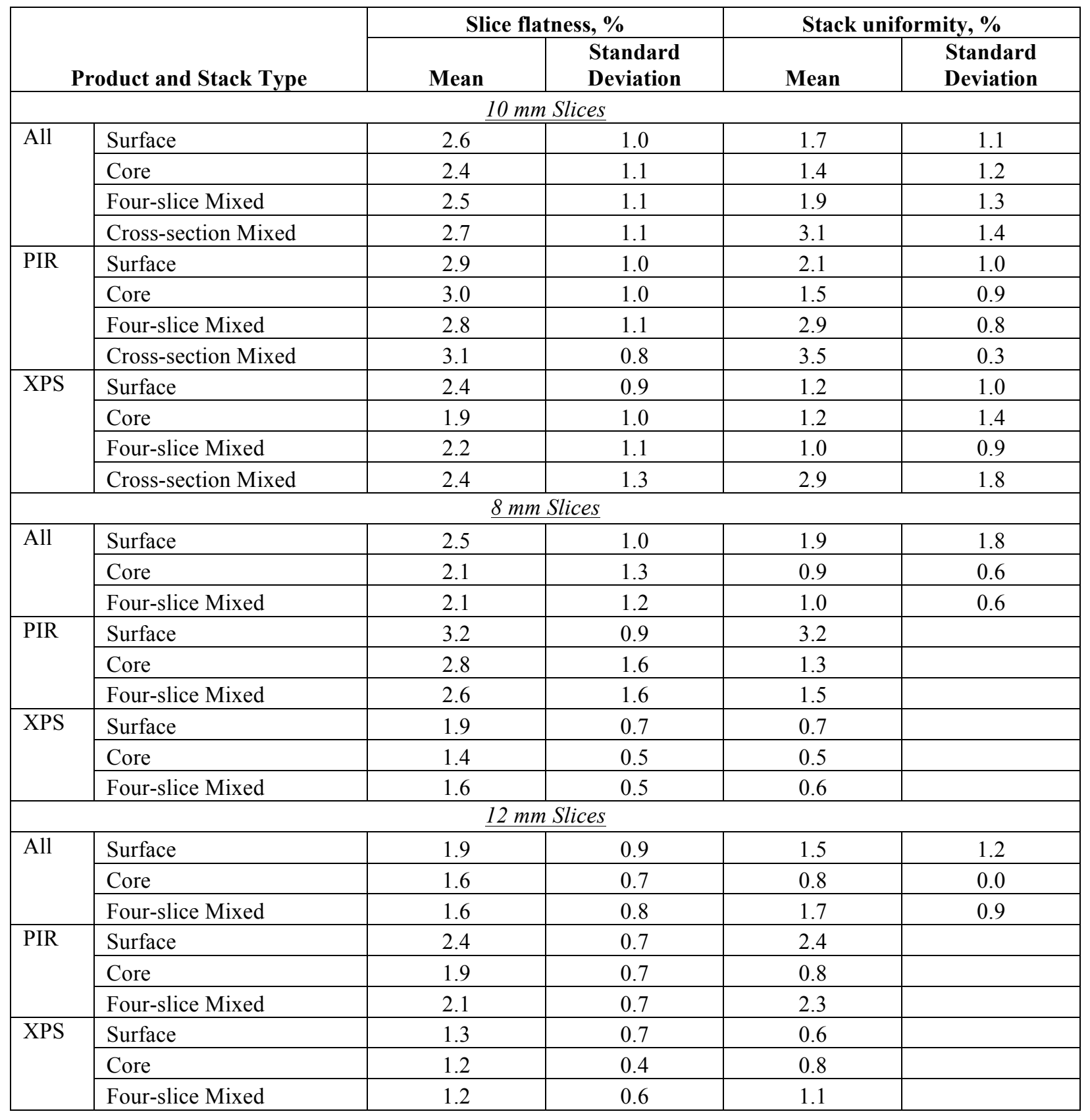




\section{B.2 Density [Stovall, 2007]}

The density of each stack was measured, as summarized in Table 16. Density is not reported for the specimens with facers. Unfortunately, the mass measurements were not always taken on the same day as the slicing. Some were measured up to 2 months later after the mass had changed due to gas diffusion. The density results therefore should only be used as a product identification variable.

\section{Table 16 Specimen density}

\begin{tabular}{|c|c|c|c|c|c|}
\hline & & & & Product & sity \\
\hline & & & Product thickness (mm) & $\left(\mathrm{kg} / \mathrm{m}^{3}\right)$ & $\left(\mathrm{lb} / \mathrm{ft}^{3}\right)$ \\
\hline & & & 25 & 28 & 1.8 \\
\hline & & All & 50 & 28 & 1.8 \\
\hline PIR & Core & & 100 & 31 & 1.9 \\
\hline & & Class1 & All & 29 & 1.8 \\
\hline & & Class2 & All & 28 & 1.8 \\
\hline & & Core and Surface & All & 27 & 1.7 \\
\hline & & & All & 28 & 1.7 \\
\hline & & & 25 & 27 & 1.7 \\
\hline & & Core & 50 & 27 & 1.7 \\
\hline & Nominal $1.7 \mathrm{lb} / \mathrm{ft}^{3}$ & & 100 & 30 & 1.9 \\
\hline & & & All & 27 & 1.7 \\
\hline & & Surface & 25 & 26 & 1.6 \\
\hline XPS & & surtace & 50 & 27 & 1.7 \\
\hline XPS & & & 100 & 28 & 1.7 \\
\hline & & Core and Surface & All & 40 & 2.5 \\
\hline & & & All & 36 & 2.3 \\
\hline & & Core & 50 & 36 & 2.3 \\
\hline & Nominal $3 \mathrm{lb} / \mathrm{ft}^{3}$ & & 100 & 36 & 2.2 \\
\hline & & & All & 43 & 2.7 \\
\hline & & Surface & 50 & 42 & 2.6 \\
\hline & & & 100 & 44 & 2.7 \\
\hline
\end{tabular}

\section{B.3 Homogeneity and alternate product thickness}

The homogeneity and alternate product thickness qualification calculations are explained in Appendix C. Summaries of these qualification test results for the ruggedness test data are shown in Table 17 and Table 18. [Stovall and Bogdan, 2007; Stovall, 2007] The homogeneity qualification test depends on a set of four ASTM C 518 test results to compare the aging behavior, over the first 30 days, of sets of slices taken from the surface and core of the material. The intent is to determine whether the foam is homogenous enough throughout its thickness so that a subset of that thickness, in the form of thin slices, can be used to adequately represent the aged thermal conductivity of the whole. Note that the values here all fall in a narrow range of 92 to $99 \%$. During the course of the analysis an alternative homogeneity measure was posited, comparing the difference between the core and surface 
stack thermal conductivity values after 30 days $/ \mathrm{cm} 2$. This alternative homogeneity measure covered a broader range, from 93 to $112 \%$.

\section{Table 17 Homogeneity Qualification Values}

\begin{tabular}{|l|l|l|c|c|}
\hline $\begin{array}{l}\text { Mater- } \\
\text { ial }\end{array}$ & Class & $\begin{array}{l}\text { Number of } \\
\text { Sets }\end{array}$ & $\begin{array}{l}\text { Range of Homogeneity } \\
\text { Age Equivalence \%o } \\
\text { (based on 30 day/cm } \\
\text { and 24 h/cm } \mathbf{~ v a l u e s ) ~}\end{array}$ & $\begin{array}{l}\text { Range of Simplified } \\
\text { Homogeneity \% (based } \\
\text { on 30 day/cm values } \\
\text { only) }\end{array}$ \\
\hline All & All & 24 & $92-99$ & $92-112$ \\
\hline PIR & All & 12 & $92-99$ & $92-101$ \\
\hline & Class 1 & 8 & $92-98$ & $92-99$ \\
\hline & Class 2 & 4 & $93-99$ & $94-101$ \\
\hline & $25 \mathrm{~mm}(1 \mathrm{inch})$ & 4 & $94-99$ & $97-99$ \\
\hline & $50 \mathrm{~mm}(2 \mathrm{inch})$ & 6 & $93-98$ & $93-99$ \\
\hline & $100 \mathrm{~mm}(4 \mathrm{inch})$ & 2 & $92-96$ & $100-112$ \\
\hline XPS & All & 12 & $96-99$ & $100-107$ \\
\hline & Lower density & 8 & $96-99$ & $103-112$ \\
\hline & Higher density & 4 & $96-98$ & $100-104$ \\
\hline & $25 \mathrm{~mm}(1 \mathrm{inch})$ & 2 & $98-99$ & $102-111$ \\
\hline & $50 \mathrm{~mm}(2 \mathrm{inch})$ & 6 & $96-98$ & 112 \\
\hline & $75-100 \mathrm{~mm}(3-4 \mathrm{inch})$ & 4 & $96-98$ & \\
\hline
\end{tabular}

The alternate product thickness criteria test seeks to determine whether the accelerated results from one product thickness can be used to predict the aged thermal performance of another product thickness. That is, can thin slices taken from a 50-mm (2-in.) thick product adequately predict the aged thermal conductivity of $25-\mathrm{mm}$ or $100-\mathrm{mm}$ (1-in. or 4 in.) thick products? Because of the comparative nature of the alternate product thickness qualification test, it requires a set of eight ASTM C 518 test results for each application of results from one product thickness to another.

These tests are used to compare the 30-day aging performance of core samples from one product thickness to core samples from another product thickness. A similar comparison is made for the surface slices. The core and surface values for these specimens range from 96 to $104 \%$, so they are all within the required range of 92 to $108 \%$.

In addition to comparing the aging rates, the absolute thermal conductivities after 30 days of aging are compared for both core and surface sets from each product thickness. The values for the core and surface thermal conductivity comparisons for these specimens ranged from 89 to $111 \%$, so some of them were outside the allowed range from 92 to $108 \%$. The results are shown in Table 18. Those sets that failed to meet the criteria are marked " $F$ ".

A proposed change is to use the average of the k-comparisons, instead of the maximum and minimum, and to tighten up the limits. The values that correspond to that proposal are shown in the last column. Every case that was disallowed under the 2007 C1303 is also disallowed with the proposed criteria, along with a few additional cases. For both criteria, all comparisons between 25 and $100 \mathrm{~mm}$ ( 1 and 4 in.) products failed the thermal conductivity comparison tests. 
Table 18 Alternate Product Thickness Qualification

\begin{tabular}{|c|c|c|c|c|c|c|c|}
\hline \multirow[b]{2}{*}{ Material } & \multirow{2}{*}{$\begin{array}{c}\text { Original } \\
\text { Product } \\
\text { thickness, } \\
\text { mm (in.) }\end{array}$} & \multirow[b]{2}{*}{ Variety } & \multirow{2}{*}{$\begin{array}{l}\text { Product } \\
\text { Thickness, } \\
\text { mm (in.) }\end{array}$} & \multirow{2}{*}{$\begin{array}{l}\text { No. } \\
\text { Comp- } \\
\text { arisons }\end{array}$} & \multicolumn{2}{|c|}{$\begin{array}{l}2007 \mathrm{C} 1303, \text { showing } \\
\text { maximum and minimum } \\
\text { from the core and surface } \\
\text { stacks }(92-108 \% \text { allowed) }\end{array}$} & \multirow{2}{*}{$\begin{array}{c}\text { Average of } \\
\text { core and } \\
\text { surface }(95- \\
105 \% \\
\text { allowed)** } \\
\mathbf{k} \\
\text { equivalence }\end{array}$} \\
\hline & & & & & $\begin{array}{c}\text { Age } \\
\text { equivalence }\end{array}$ & $\begin{array}{c}\mathbf{k} \\
\text { equivalence }\end{array}$ & \\
\hline \multirow[b]{8}{*}{ PIR } & \multirow[b]{3}{*}{$25(1)$} & \multirow[b]{2}{*}{ Class 1} & $50(2)$ & 1 & $99-101$ & $104-109 \mathrm{~F}^{*}$ & $107 \mathrm{~F}$ \\
\hline & & & $100(4)$ & 2 & $96-99$ & $88-98 \mathrm{~F}$ & $91-97 \mathrm{~F}$ \\
\hline & & Class 2 & $50(2)$ & 2 & $96-101$ & $95-106$ & $97-103$ \\
\hline & \multirow[b]{3}{*}{$50(2)$} & \multirow[b]{2}{*}{ Class 1} & $25(1)$ & 4 & $99-102$ & $91-110 \mathrm{~F}$ & $93-105 \mathrm{~F}$ \\
\hline & & & $100(4)$ & 4 & $97-103$ & $102-105$ & $102-104$ \\
\hline & & Class 2 & $25(1)$ & 2 & $99-104$ & $94-105$ & $97-103$ \\
\hline & \multirow[b]{2}{*}{$100(4)$} & \multirow[b]{2}{*}{ Class 1} & $25(1)$ & 2 & $101-104$ & $102-112 \mathrm{~F}$ & $103-109 \mathrm{~F}$ \\
\hline & & & $50(2)$ & 2 & $99-103$ & $95-97$ & $96-97$ \\
\hline \multirow[b]{8}{*}{ XPS } & \multirow[b]{2}{*}{$25(1)$} & \multirow[b]{2}{*}{ Standard } & $50(2)$ & 2 & $97-99$ & $101-104$ & $101-103$ \\
\hline & & & $100(4)$ & 2 & $96-99$ & $88-90 \mathrm{~F}$ & $89 \mathrm{~F}$ \\
\hline & \multirow[b]{3}{*}{$50(2)$} & \multirow[b]{2}{*}{ Standard } & $25(1)$ & 4 & $101-103$ & $96-101$ & $97-101$ \\
\hline & & & $100(4)$ & 4 & $98-102$ & $102-106$ & $102-104$ \\
\hline & & High & $75(3)$ & 2 & $97-100$ & $100-107$ & $101-107 \mathrm{~F}$ \\
\hline & \multirow{3}{*}{$\begin{array}{l}75-100(3- \\
4)\end{array}$} & \multirow{3}{*}{$\begin{array}{l}\text { Standard } \\
\text { Hioh }\end{array}$} & $25(1)$ & 2 & $101-104$ & $110-112 \mathrm{~F}$ & $111 \mathrm{~F}$ \\
\hline & & & $50(2)$ & 2 & $100-102$ & $94-98$ & $96-98 \mathrm{~F}$ \\
\hline & & & $50(2)$ & 2 & $100-103$ & $93-100$ & $93-99 F$ \\
\hline
\end{tabular}

\section{B.4 Thickness of the destroyed surface layer [Stovall and Bogdan, 2007]}

The cell morphology and the cutting equipment determine the thickness of the destroyed surface layer, TDSL. This thickness is important in determining the true diffusion thickness of a slice because the broken cells are essentially immediately filled with atmospheric gases when the slice is cut. Using a gas displacement technique, the TDSL is calculated using the difference between geometric volume and effective volume divided by the surface area of each specimen according to ASTM D6226. [ASTM International (d)] The results for representative specimens cut along with the thin slices for this ruggedness test are summarized in Table 19. Each TDSL was measured on triplicate specimens. Two previous interlaboratory ruggedness tests examined the influence of cutting equipment and TDSL measurement technique on the measured TDSL [Fabian, et al., 1997; Stovall, 2006]. The results from this previous study labeled "Lab A," "Lab B," and "Lab C" are summarized in Figure 16 and compared to the results from this study, labeled "Lab D." 
Table 19 Measured TDSL values for a subset of the test specimens

\begin{tabular}{|l|l|c|c|c|}
\hline \multicolumn{1}{|c|}{ Product } & \multicolumn{1}{|c|}{ Group } & $\begin{array}{c}\text { Full product } \\
\text { thickness, mm (in.) }\end{array}$ & TDSL (mm) & $\begin{array}{c}\text { Standard } \\
\text { deviation (mm) }\end{array}$ \\
\hline \multirow{3}{*}{ PIR } & Class 1 & $50(2)$ & 0.483 & 0.019 \\
\cline { 2 - 5 } & & $100(4)$ & 0.468 & 0.025 \\
\cline { 2 - 5 } & Class 2 & $50(2)$ & 0.409 & 0.024 \\
\hline \multirow{3}{*}{ XPS } & \multirow{3}{*}{ Standard } & $25(1)$ & 0.490 & 0.026 \\
\cline { 3 - 5 } & & $50(2)$ & 0.647 & 0.024 \\
\cline { 2 - 5 } & \multirow{2}{*}{ High } & $50(2)$ & 0.683 & 0.036 \\
\cline { 3 - 5 } & & $50(2)$ & 0.428 & 0.035 \\
\cline { 3 - 5 } & & $75(3)$ & 0.426 & 0.003 \\
\hline
\end{tabular}

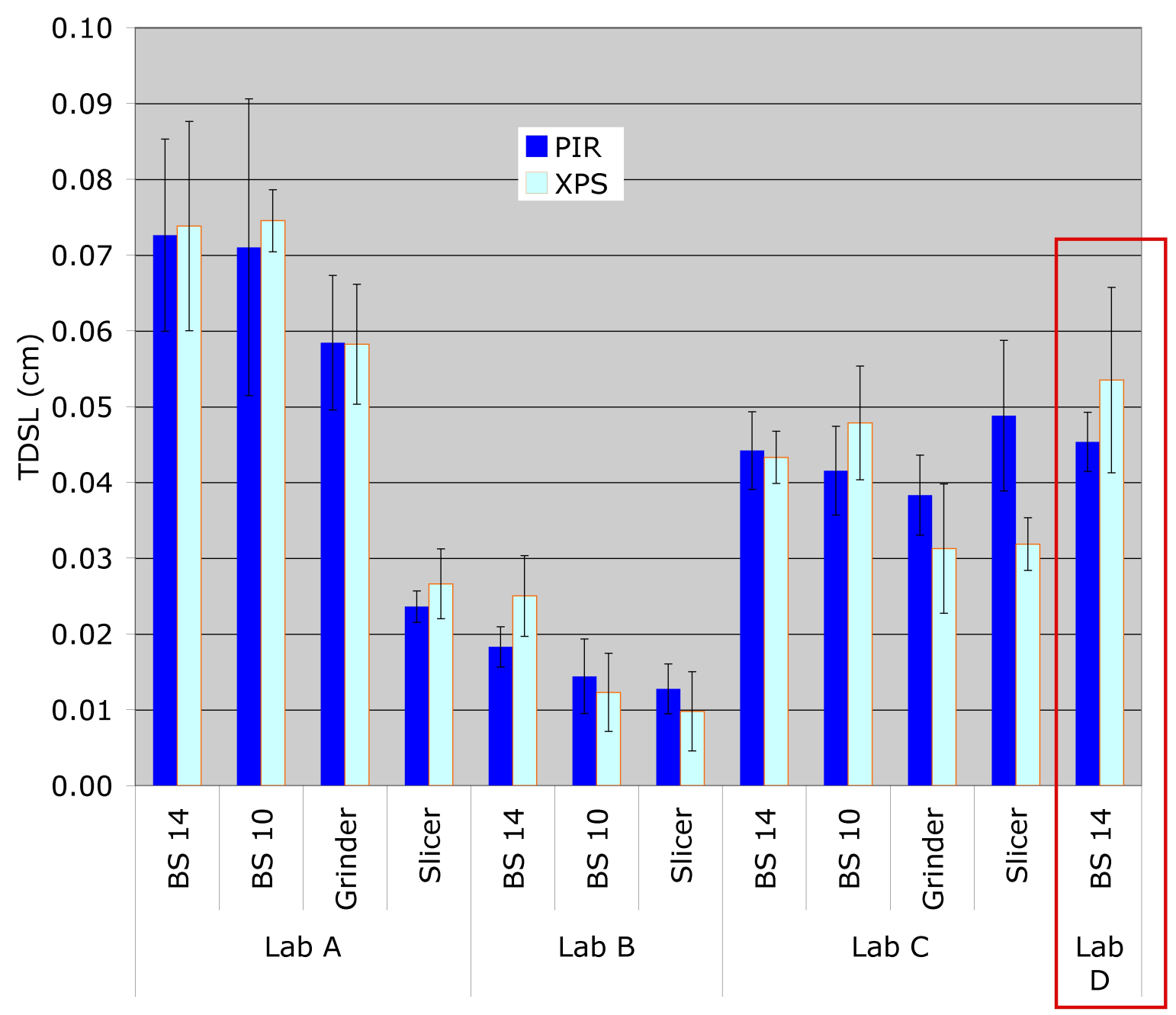

Figure 16 TDSL measurement results (Lab D results from specimens prepared for current ruggedness test. For comparison, data from Labs A, B, C are provided from previous slice preparation ruggedness test. "BS14" and "BS10" are bandsaws with 14 and 10 teeth per inch, respectively.) 


\section{APPENDIX C. C1303-2007 QUALIFICATION REQUIREMENTS AND PROPOSED MODIFICATIONS TO THOSE REQUIREMENTS}

Qualification tests were defined in the 2007 version for both product homogeneity and the use of data from alternate product thicknesses

\section{C.1 Homogeneity}

As discussed above, the theoretical foundation for thin-slice age acceleration test method applies rigorously for homogenous foam. In real products, especially in faced-products, the surface foam region may provide additional gas diffusion resistance and therefore retard the aging process. There have also been questions regarding the degree to which portions of the foam cross section must be similar, or homogenous, for the age acceleration process to produce an acceptably accurate prediction of the full-thickness aged thermal conductivity.

A previous version of ASTM C 1303 defined a foam product as sufficiently homogenous if the slope of the thermal conductivity versus the normalized time during the first stage of aging didn't vary more than $10 \%$ between multiple specimens taken from the core and surface regions. ${ }^{2}$ As shown in Figure 17, this criterion left the definition of the 'first stage' of aging to the user.

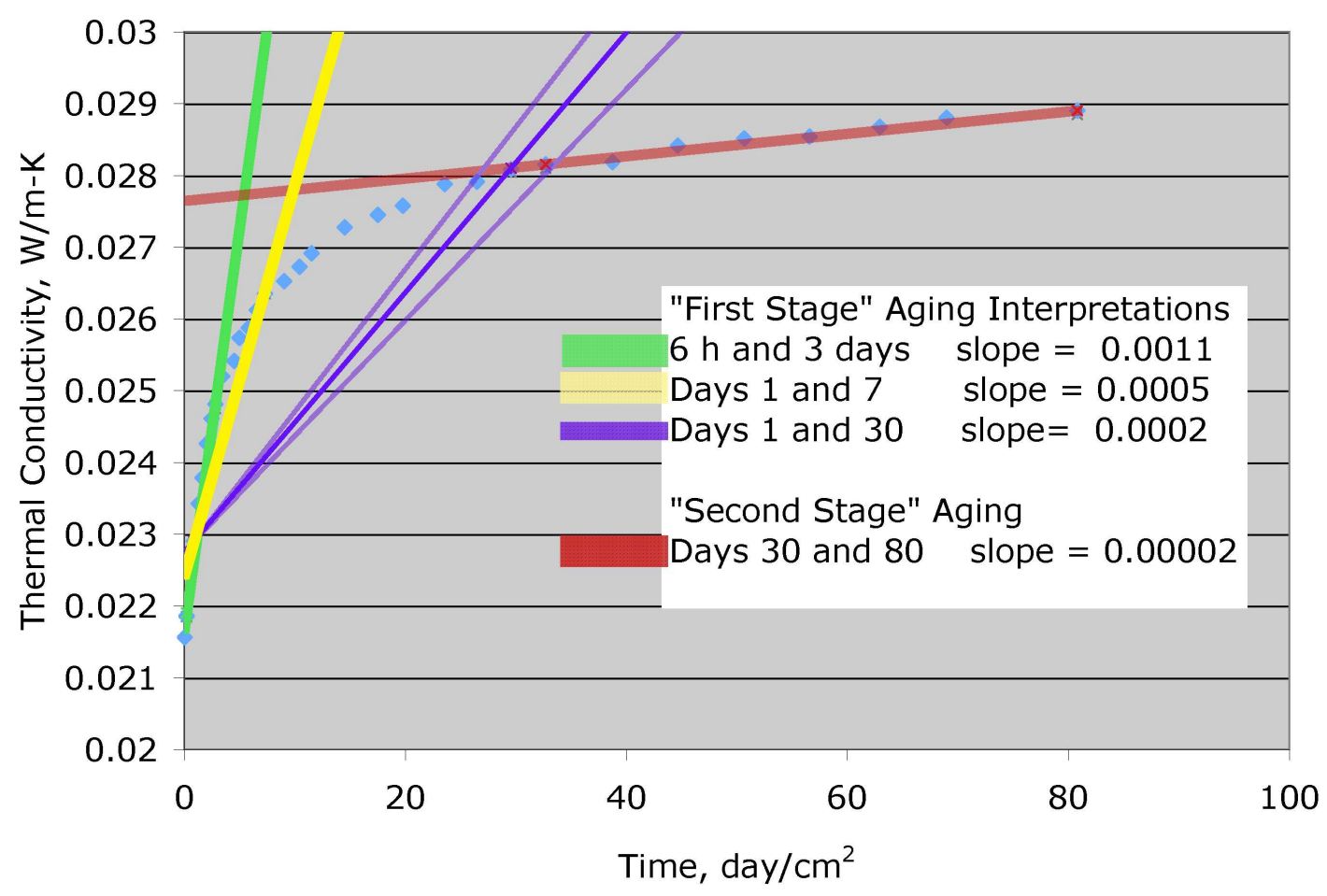

Figure 17 Homogeneity criteria from ASTM C1303 (2000), showing the 10\% acceptable bounds for an aging slope based upon data from days 1 and 30.

2 The normalized time was the time divided by the square of the slice thickness. 
In revising the standard to produce a more prescriptive method, the method of examining the first stage of aging was altered into an "age equivalence" qualification criteria, shown in Eq. 11 based upon the 'aging factor' ratio approach from CAN/ULC S770.[ Underwriters Laboratory of Canada] In this qualification test, the change in thermal conductivity over a period of time of approximately one month for surface slices is compared to the corresponding change for core slices over the same normalized time period. One of the objectives of the ruggedness test is to determine an appropriate 'passing grade' for these criteria. The criteria were arbitrarily set at a broad level pending the results from this study.

$$
\text { Age Equivalence }=100 \%\left\{1-\frac{2\left[\left(\frac{k_{24 h / \mathrm{cm}^{2}}}{k_{30 \mathrm{~d} / \mathrm{cm}^{2}}}\right)_{\text {surface }}-\left(\frac{k_{24 \mathrm{~h} / \mathrm{cm}^{2}}}{k_{30 \mathrm{~d} / \mathrm{cm}^{2}}}\right)_{\text {core }}\right]}{\left[\left(\frac{k_{24 h / \mathrm{cm}^{2}}}{k_{30 \mathrm{~d} / \mathrm{cm}^{2}}}\right)_{\text {surface }}+\left(\frac{k_{24 \mathrm{~h} / \mathrm{cm}^{2}}}{k_{30 \mathrm{~d} / \mathrm{cm}^{2}}}\right)_{\text {core }}\right]}\right\}
$$

where:

$\mathrm{k}=\quad$ thermal conductivity, $\mathrm{W} / \mathrm{m}-\mathrm{K}$

During this study, there was no relationship between a "better homogeneity" as defined in Eq. 10 and a more accurate prediction of the five-year thermal conductivity. That indicates that the factory-manufactured foam boardstock tested here is sufficiently homogenous for the accelerated test method. Every product tested producing a value between 92 and 99\% per Eq. 10 .

Considering that some form of homogeneity criteria would still be useful for new product formulations and for insulation foam products not included in this ruggedness evaluation, an alternative definition for homogeneity is proposed, as shown in Eq. 12. This simpler approach compares the absolute values of thermal conductivity of the core and surface slices after $30 \mathrm{~d} / \mathrm{cm}^{2}$ instead of the ratios at two points in time. Based on the results of this ruggedness test, these two forms are closely related and the simpler form would be easier and therefore more economical. This produces a broader range of values, so the qualification criteria would need to be broadened to 85 to $115 \%$ from the current 90 to $110 \%$, as shown in Figure 18 and Table 17.

$$
H_{\text {simplified }}=100 \%\left\{1-\frac{\left(k_{\text {core }}-k_{\text {surface }}\right)}{k_{\text {surface }}}\right\}
$$




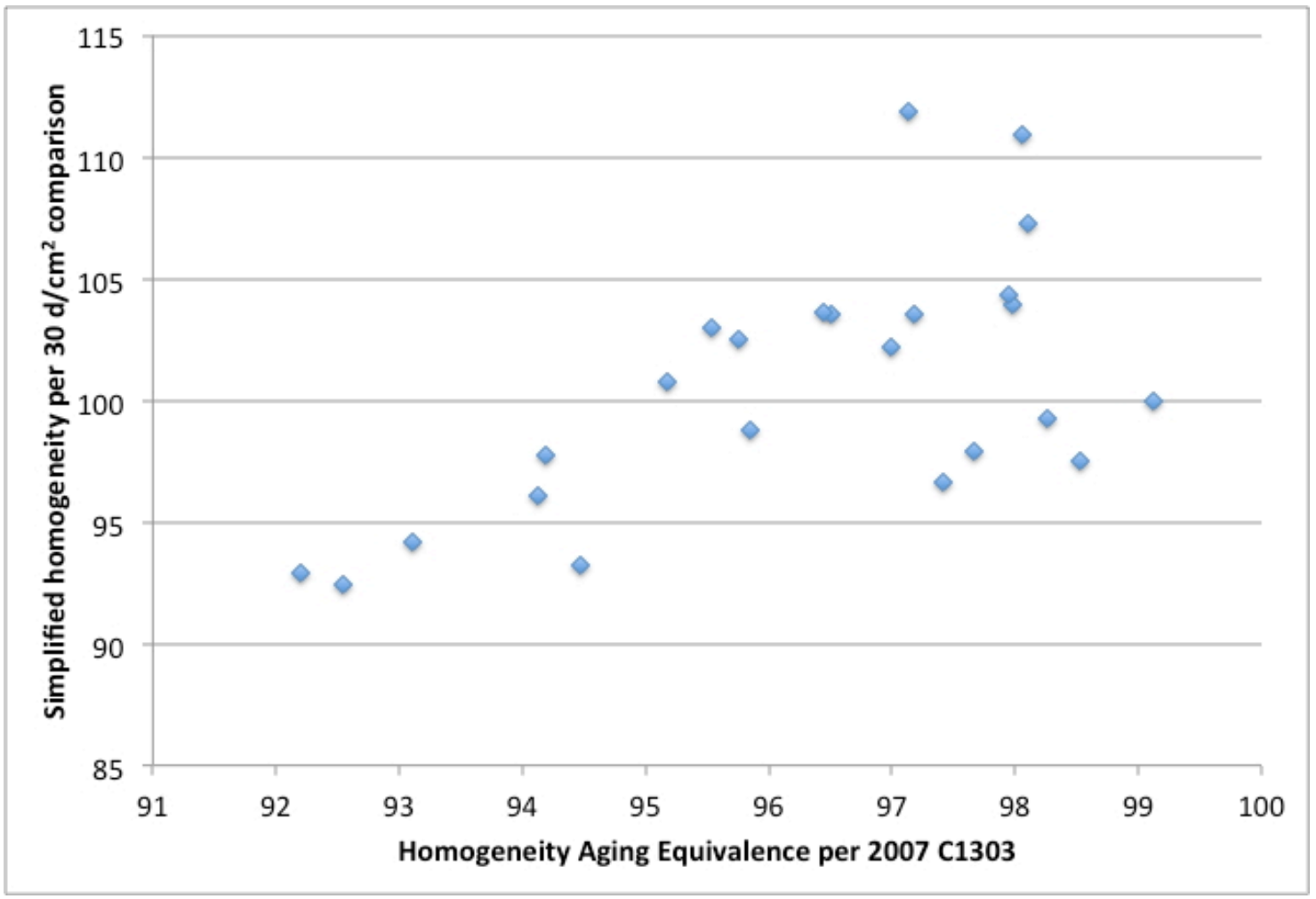

Figure 18 Comparing the $2007 \mathrm{C} 1303$ homogeneity calculation to a proposed simplified version.

\section{C.2 Alternate product thickness qualification}

The $2007 \mathrm{C} 1303$ has two qualification requirements for alternate thickness predictions. First the core and surface stacks from each product thickness must age at similar rates over the first $30 \mathrm{~d} / \mathrm{cm}^{2}$, as shown in Eq. 13 and Eq. 14. Second, the core and surface stacks from each product thickness must have similar thermal conductivities, as shown in Eq. 15 and Eq. 16. All four of these comparisons were required to fall between 92 and $108 \%$ to satisfy the 2007 C1303 qualification requirements for an alternate thickness prediction.

Age Equivalence core $=100 \%\left\{1-\frac{2\left[\left(\frac{k_{24 h / \mathrm{cm}^{2}}}{k_{30 \mathrm{~d} / \mathrm{cm}^{2}}}\right)_{\text {core, product } 1}-\left(\frac{k_{24 h / \mathrm{cm}^{2}}}{k_{30 \mathrm{~d} / \mathrm{cm}^{2}}}\right)_{\text {core, product } 2}\right]}{\left[\left(\frac{k_{24 h / \mathrm{cm}^{2}}}{k_{30 \mathrm{~d} / \mathrm{cm}^{2}}}\right)_{\text {core, product 1 }}+\left(\frac{k_{24 h / \mathrm{cm}^{2}}}{k_{30 \mathrm{~d} / \mathrm{cm}^{2}}}\right)_{\text {core, product 2 } 2}\right]}\right\}$

Age Equivalence surface $=100 \%\left\{1-\frac{2\left[\left(\frac{k_{24 h / \mathrm{cm}^{2}}}{k_{30 \mathrm{~d} / \mathrm{cm}^{2}}}\right)_{\text {surface, product 1 }}-\left(\frac{k_{24 / \mathrm{cm} \mathrm{c}^{2}}}{k_{30 \mathrm{~d} / \mathrm{cm}^{2}}}\right)_{\text {sufface, product 2 }}\right]}{\left[\left(\frac{k_{24 h / \mathrm{cm}^{2}}}{k_{30 \mathrm{~d} / \mathrm{cm}^{2}}}\right)_{\text {sufface,product } 1}+\left(\frac{k_{24 h / \mathrm{cm}^{2}}}{k_{30 \mathrm{~d} / \mathrm{cm}^{2}}}\right)_{\text {surface, product 2 }}\right]}\right\}$ 


$$
\begin{aligned}
& \text { k Equivalence } \text { core }=100 \%\left\{1-\frac{2\left[\left(k_{30 \mathrm{~d} / \mathrm{cm}^{2}}\right)_{\text {core, product 1 }}-\left(k_{30 \mathrm{~d} / \mathrm{cm}^{2}}\right)_{\text {core, } \text { product } 2}\right]}{\left[\left(k_{30 \mathrm{~d} / \mathrm{cm}^{2}}\right)_{\text {core, product 1 }}+\left(k_{30 \mathrm{~d} / \mathrm{cm}^{2}}\right)_{\text {core, } \text { product 2 }}\right]}\right\}
\end{aligned}
$$

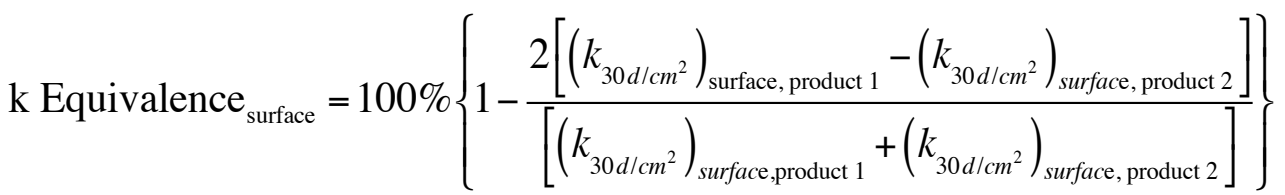

In the ruggedness trial, every comparison between products of different thicknesses met the aging requirements in Eq. 13 and 14. Most, but not all, met the requirements in Eq. 15 and 16 .

It is proposed here that the alternate thickness qualification requirements be modified to delete the aging comparisons. Rather than requiring the surface and core k-equivalence be independently met, it is proposed that the average of those two values be required to be between 95 and $105 \%$. This was found to serve as a more effective screen based upon the errors in the five-year predictions than the 2007 C1303 criteria. 


\section{REFERENCES}

ASTM International (a) C 1303, Standard Test Method for Predicting Long-Term Thermal Resistance of Closed-Cell Foam Insulation, Annual Book of ASTM Standards, ASTM International, West Conshohocken, PA, www.astm.org, (relevant versions published in 1995, 2000, 2007, and 2012)

ASTM International (b) D1622 "Standard Test Method for Apparent Density of Rigid Cellular Plastics," Annual Book of ASTM Standards, ASTM International, www.astm.org, West Conshohocken, PA.

ASTM International (c) Standard C518, "Standard Test Method for Steady-State Thermal Transmission Properties by Means of the Heat Flow Meter Apparatus," Annual Book of ASTM Standards, ASTM International, www.astm.org, West Conshohocken, PA.

ASTM International (d) D6226 "Standard Test Method for Open Cell Content of Rigid Cellular Plastics," Annual Book of ASTM Standards, ASTM International, www.astm.org, West Conshohocken, PA.

ASTM International (e) E1169 - 07 "Standard Practice for Conducting Ruggedness Tests,” Annual Book of ASTM Standards, ASTM International, www.astm.org, West Conshohocken, PA.

Ball, J. S., Healey, G. W., and Partington, J. B., 1978, "Thermal Conductivity of Isocyanate-Based Rigid Cellular Plastics: Performance in Practice,” European Journal of Cellular Plastics, 1978, pp. 50-62.

Bomberg, M. T., 1990, "Scaling Factors in Aging of Gas-Filled Cellular Plastics," Journal of Thermal Insulation, Vol 13, January 1990, p. 149.

Booth, J. R., 1980, "R-Value Aging of Rigid Urethane Foam Products," Proceedings, Society of Plastics Industry of Canada, 1980.

Drouin, M., 2009, Supporting Data for ASTM C1289-02 Specification for Faced Rigid Cellular Polyisocyanurate Thermal Insulation Board, ASTM Research Report C16-1035, March 31, 2009, ASTM International, West Conshohocken, PA

Edgecombe, F. H., 1989, "Progress in Evaluating Long-Term Thermal Resistance of Cellular Plastics, CFCS \& Polyurethane Industry: Volume 2," A Compilation of Technical Publications 1988-1989, F. W. Lichtenburg, ed., Technomic Publishing Co., pp. 17-24.

Fabian, B. A., Graves, R. S., Hofton, M. R., and Yarbrough, D. W., 1997, “A Variability Study on the ASTM Thin Slicing and Scaling Test Method for Evaluating the Long-Term Performance of an Extruded Polystyrene Foam Blown with HCFC-142b," Insulation Materials: Testing and Applications: Third Volume, ASTM STP 1320, ASTM 1997, pp. $197-215$.

Gill, J., 2001, Interpreting interactions and Interaction Hierarchies in Generalied Linear Models: Issues and Applications, American Political Science Association Annual Meeting, San Francisco, CA, September 2001

Glicksman, L. R., 1994, "Heat Transfer in Foams," Chapter 5 in Low Density Cellular Plastics, Physical Basis of Behaviour, Hilyard, N. C., and Cunningham, A., Eds., Chapman \& Hall, London, 1994. 
Graves, R. S., McElroy, D. L., Weaver, F. J., and Yarbrough, D. W., 1995, "Interlaboratory Comparison on Estimating the Long-Term Thermal Resistance of Unfaced, Rigid, Closed-Cell, Polyisocyanurate (PIR) Foam Insulation-A Cooperative Industry/Government Project," Oak Ridge National Laboratory Report ORNL/M-3976, January 1995.

Hoogendoorn, C.J. 1994. "Thermal Ageing”, Chapter 6 in Low Density Cellular Plastics Physical Basis of Behaviour, N.C. Hilyard and A. Cunningham, eds., Chapman \& Hall, London, pp. 153-186

Isberg, J., 1988, “Thermal Insulation-Conditioning of Rigid Cellular Plastics Containing a Gas with Lower Thermal Conductivity than Air Prior to Determination of Thermal Resistance and Related Properties," Chalmers University of Technology, No. 698, Goteborg, Sweden, 1988.

Kumaran, M. K., and Bomberg, M. T., 1990, "Thermal Performance of Sprayed Polyurethane Foam Insulation with Alternative Blowing Agents," Journal of Thermal Insulation, Vol 14, July 1990, pp. 43-58.

McElroy, D. L., Graves, R. S., Weaver, F. J., and Yarbrough, D. W., 1991, “The Technical Viability of Alternative Blowing Agents in Polyisocyanurate Roof Insulation," Part 3: Acceleration of Thermal Resistance Aging Using Thin Boards, Polyurethanes 90 Conference Proceedings, Orlando, FL, 1991.

Miller, R. G. J., 1981, Simultaneous Statistical Inference, New York: Springer-Verlag.

Mullenkamp, S. P., and Johnson, S. E., 1983, "In-Place Thermal Aging of Polyurethane Foam Roof Insulations," 7th Conference on Roofing Technology, National Roofing Contractors Association, 1983.

Pasta, David J., 2011, "Those confounded interactions: Building and interpreting a model with many potential confounders and interactions," Proceedings of the SAS Global Forum 2011, 347-2011 http://support.sas.com/resources/papers/proceedings11/347-2011.pdf

SAS Institute, Inc., Cary, NC, 2007

Scheutz, M. A., and Glicksman, L. R., 1983, "A Basic Study of Heat Transfer Through Foam Insulations," Proceedings of the Sixth International Polyurethane Conference, San Diego, CA, 1983, pp. 341-347.

Searle, S. R., F. M. Speed and G. A. Milliken (1980), Population Marginal Means in the Linear Model: An Alternative to Least Squares Means, The American Statistician, Vol. 34, No. 4 (Nov., 1980), pp. 216-221

Stovall, T. K., Fabian, B. A., Nelson, G. E., and Beatty, D. R., 2002, “A Comparison of Accelerated Aging Test Protocols for Cellular Foam Insulation," Insulation Materials: Testing and Applications: 4th Volume, ASTM STP 1426, A. O. Desjarlais and R. R. Zarr, Eds., American Society for Testing and Materials, West Conshohocken, PA, 2002.

Stovall, T. K. and Bogdan, M., 2007, "Measuring the Impact of Experimental Parameters upon the Estimated Thermal Conductivity of Closed-Cell Foam Insulation Subjected to an Accelerated Aging Protocol," Proceedings of the 29th International Thermal Conductivity Conference, Birmingham, AL, June, 2007, Technomic Publications, PA. 
Stovall, T. K., 2007, "Interlaboratory Comparison of the Thickness of the Destroyed Surface Layer of Closed-cell Foam Insulation Specimens," Presented at ASTM Symposium on Heat-Air-Moisture Transport: Measurements on Building Materials on 23-26 April 2006 in Toronto, Canada; P. Mukhopadhyaya and M. Kumaran, Guest Editors, Journal of ASTM International, Vol. 4, No 1, Paper ID JAI100321, December 2006

Stovall, T. K., 2009, "Measuring the Impact of Experimental Parameters upon the Estimated Thermal Conductivity of Closed-Cell Foam Insulation Subjected to an Accelerated Aging Protocol: Two-Year Results," Journal of ASTM International, Vol. 6, No. 5, Paper ID JAI102025, April 2009, Available online at www.astm.org

Underwriters Laboratory of Canada, CAN/ULC S770 Standard Test Method for Determination of Long-Term Thermal Resistance of Closed-Cell Thermal, Northbrook, IL 60062-2096 USA,www.ulc.ca 